\title{
Underwater Laser Welding/Cladding for High-performance Repair of Marine Metal Materials: A Review
}

\author{
Guifang Sun ${ }^{*}$, Zhandong Wang, Yi Lu, Mingzhi Chen, Kun Yang and Zhonghua Ni
}

\begin{abstract}
With the rapid developments of marine resource exploitation, mounts of marine engineering equipment are settled on the ocean. When it is not possible to move the damaged equipment into a dry dock, welding operations must be performed in underwater environments. The underwater laser welding/cladding technique is a promising and advanced technique which could be widely applied to the maintenance of the damaged equipment. The present review paper aims to present a critical analysis and engineering overview of the underwater laser welding/cladding technique. First, we elaborated recent advances and key issues of drainage nozzles all over the world. Next, we presented the underwater laser processing and microstructural-mechanical behavior of repaired marine materials. Then, the newly developed powder-feeding based and wire-feeding based underwater laser direct metal deposition techniques were reviewed. The differences between the convection, conduction, and the metallurgical kinetics in the melt pools during underwater laser direct metal deposition and in-air laser direct metal deposition were illustrated. After that, several challenges that need to be overcame to achieve the full potential of the underwater laser welding/ cladding technique are proposed. Finally, suggestions for future directions to aid the development of underwater laser welding/cladding technology and underwater metallurgical theory are provided. The present review will not only enrich the knowledge in the underwater repair technology, but also provide important guidance for the potential applications of the technology on the marine engineering.
\end{abstract}

Keywords: Underwater laser welding, Underwater laser direct metal deposition, Drainage nozzle, Marine metal materials, Mechanical property, Diffusible hydrogen

\section{Introduction}

Surface cracking and damage, including seawater corrosion, abrasion and surface fatigue cracks, are very likely to generate on the marine engineering equipment. Unpredicted failures of the marine engineering equipment may be caused those surface damages. Generally, it is often at great cost and impracticable to move the damaged marine engineering equipment to the dry dock to finish the repair work. The estimated time and cost

*Correspondence: gfsun@seu.edu.cn; nzh2003@seu.edu.cn School of Mechanical Engineering, Jiangsu Key Laboratory for Design and Manufacture of Micro-Nano Biomedical Instruments, Southeast University, Nanjing 211189, China for dry welding repairs are twice those for wet welding repair [1]. Thus, it is of great significance to develop onsite repair techniques to restore the performance of the damaged offshore engineering equipment. The underwater welding technique is generally considered as the most important technique to apply to the repair and maintenance of marine engineering equipment.

Underwater welding techniques are widely used in the construction of marine engineering equipment which includes crude oil transmission pipeline, offshore drilling platform, underwater manned submersible and watercraft. The underwater welding technique has been developed by many countries, such as Japan, America, Germany, Poland and China for the past thirty years 
[2-6]. The commonly employed repair techniques are composed of underwater arc welding (UAW) and newly developed underwater laser beam welding (ULBW). The UAW technique consists of underwater dry welding, underwater wet welding and underwater local dry welding [7].

Over the past decades, research has been conducted on the development of underwater wet welding technique. During the underwater wet welding, the electrode, welded material and welder are all in direct contact with the water [4]. When the underwater wet welding is directly carried out in underwater environments, the surrounding water can deteriorate the arc stability. The instability of arc results from the complex interaction among bubbles, arc, melt droplets and ambient pressure in underwater environments [8-10]. When the steels are welded by the underwater wet welding, cold cracking and hydrogen induced cracking are prone to occur in the butt joints because of the high hardness and the high diffusible hydrogen content $[5,11]$. The cooling effect of the surrounding water and generation of considerable amounts of hydrogen lead to the poor properties of the as-welded material [4]. Generally, the adverse influence of the water environment can be excluded by both underwater dry welding and underwater local dry welding techniques.

For underwater dry welding, a highly specialized chamber is employed to generate a water-free zone for marine metal structures to be welded [12]. However, the welding system for underwater dry welding is much more expensive [4]. The emergence of underwater local dry welding technology has solved this problem [13]. Compared with underwater dry welding, underwater local dry welding would cost less and the post-repair performance would not be degraded [13, 14]. It is reported that the butt joints with excellent toughness and high strength can be obtained by the underwater local dry welding [15, 16]. Underwater local dry welding is considered as one of the most promising methods in the field of underwater welding repair [17]. At the same time, the local dry drainage device is considered as one of the key components of underwater remote control welding equipment [18].

Nowadays, with the rapid developments of high-power laser devices, laser welding has gradually replaced the traditional welding techniques and become the key technology for the welding with high quality. Additionally, laser welding is especially suitable for the welding of steel materials with large thickness [19]. The underwater laser beam welding/cladding has been developed for the past twenty years because of its low heat accumulation, excellent stability, precise heat input and high power density of laser [20-23]. Unlike land, the underwater environment has a critical influence on the manufacturing process and metallurgical process during the underwater welding process. When the laser irradiated water, then water can strongly shield the laser beam, resulting in the reduction of the absorption efficiency of laser upon the work surface [24]. The formation of a dry region that can be acted as a beam channel is necessary for the successful implement of underwater laser welding [25]. Therefore, a drainage device is needed to produce a dry area on the surface of damaged marine structure to keep the water away and ensure the operation flexibility and high manufacturing quality.

The underwater laser welding/cladding technology is so new that the corresponding literatures about this technology are limited. Although several recent studies have focused on this technology $[20,21,24,26]$, none of state-of-the-art has summarized and reviewed the development histories and the latest advances of the underwater laser welding/cladding technology. This underwater manufacturing technology has shown great application prospects towards the repair of marine metal structures. This is the primary motivation for this work as a comprehensive study on the key aspects and research trends for the development of drainage nozzles and further studies of this new technology.

In this work, we first summarize the developments and applications of drainage nozzles utilized in underwater laser welding/cladding processes. Then the relationship between the underwater laser welding/cladding processes and microstructural-mechanical properties of repaired marine metal materials is thoroughly reviewed. At last, the problems, challenges, and the further developments in the field of underwater laser welding/cladding are proposed. The engineering overview from this work highlights the promising outlook for the development of advanced underwater laser processing technologies towards on-site repair of marine metal materials with high performance.

\section{Developments of Drainage Nozzles for Underwater Laser Welding/Cladding Processes}

\subsection{Drainage Nozzles with Gas Drainage Method}

In 1996, GKSS Forschungszentrum Geesthacht in Germany developed a sealed nozzle [6]. This nozzle can produce and maintain a dry working space with acceptable gas flows and an extension range of $4 \mathrm{~mm}$ (Figure 1(a)). The developed underwater drainage nozzle was tested successfully during the underwater welding repair of a stainless steel pipe at a water depth of $3 \mathrm{~m}$. In 1997, Ishikawajima-Harima Heavy Industries Co., Ltd. (IHI) in Japan reported a simple underwater laser wire feeding welding drainage device [27]. This device is characterized by a small drainage radius, and the protective gas is also 

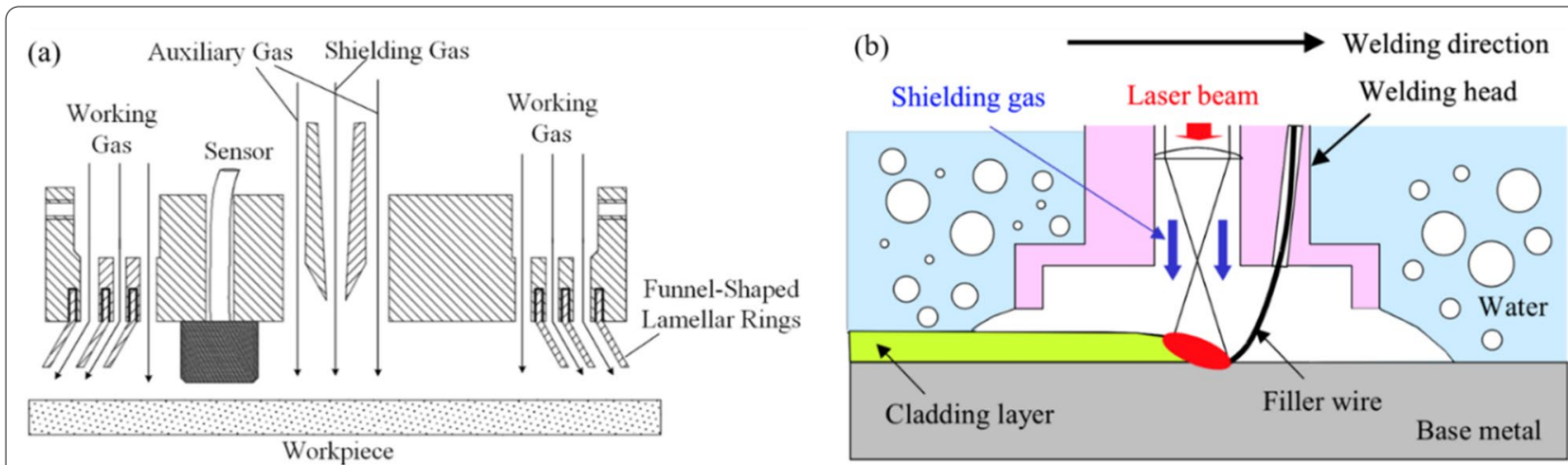

Figure 1 Schematic of gas curtain nozzle (a) developed by GKSS in Germany [6] and (b) developed by Toshiba in Japan [28]

the drainage gas. The developed device can be used in the drainage work of flat welding and overhead welding. In 2006, Toshiba in Japan developed a ULBW technique to repair underwater equipment which suffers from stress corrosion cracking [28]. During the ULBW process, a local dry area can be created with the help of shielding gas injected from the laser welding head. The schematic of the ULBW process is presented in Figure 1(b).

In 2018, Guo et al. [20] from Harbin Institute of Technology in China designed a double-layer gas curtain nozzle which can be used for the formation of a local dry area (Figure 2(a)). This gas curtain nozzle has several features, such as reduction of the use of inert gas, stable local dry area and reduction of the welding cost. The compressed air from the air compressor is transmitted to the outer layer of the double-layer gas curtain nozzle and the shielding gas is delivered to the inner layer of the nozzle. Meantime, in 2018, the authors' group [29] from Southeast University in China designed two types of gas curtain nozzles to generate a local dry area in underwater environments. The first type of gas curtain nozzle is presented in Figure 3(a). Based on the first type of nozzle, in 2018, the authors' group also designed a gas curtain nozzle with an annular buffer to generate a more stable local dry area (Figure 2(b)). The innovative structure of buffer near the processing area of the gas curtain nozzle can strengthen the stability of dry area. The annular buffer can increase the drainage depth, which is verified by a group of numerical simulations about the flow field of different drainage models. Additionally, Wang et al. [30] from South China University of Technology in China developed a set of miniature drainage device, as shown in Figure 3(c), (d). This nozzle consists of specially designed inlets, outer nozzle and composites made waterproof. A

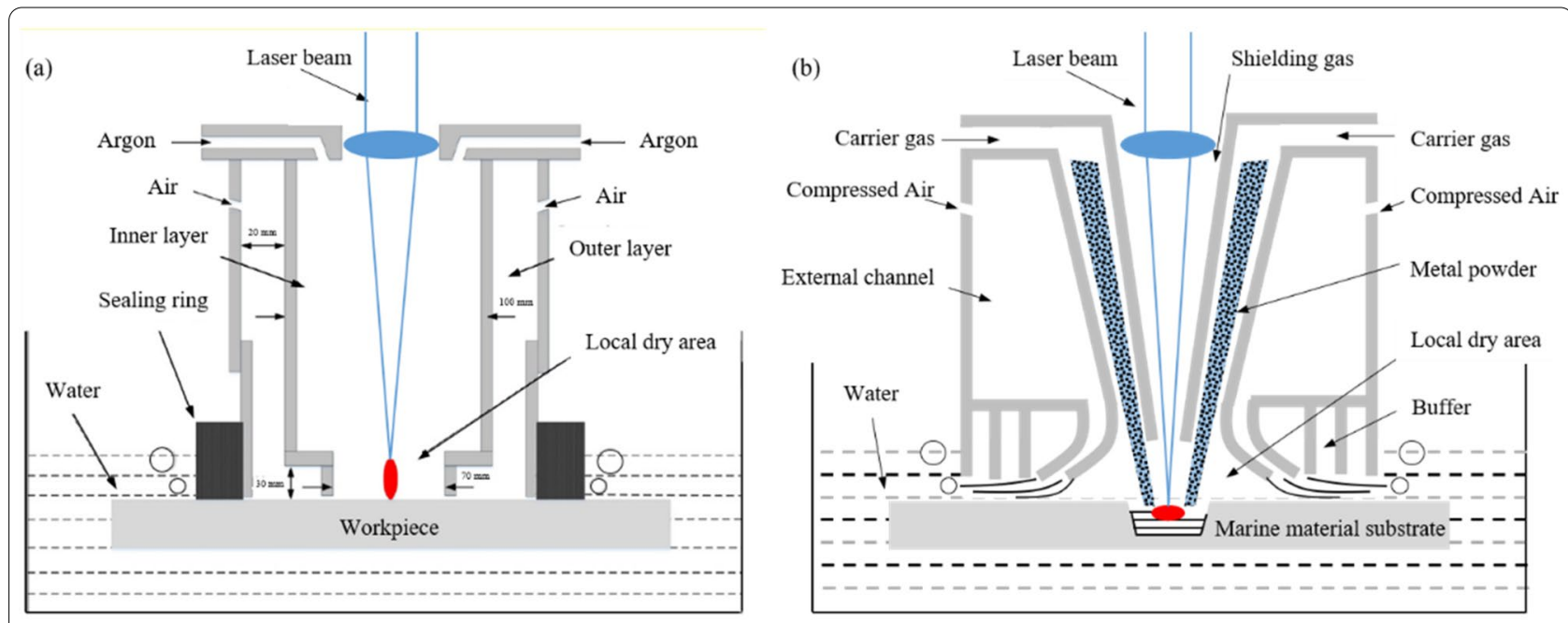

Figure 2 Schematic of (a) a double-layer gas curtain nozzle developed by Harbin Institute of Technology in China [20] and (b) a gas curtain nozzle with an annular buffer developed by the author's group in Southeast University in China [29] 

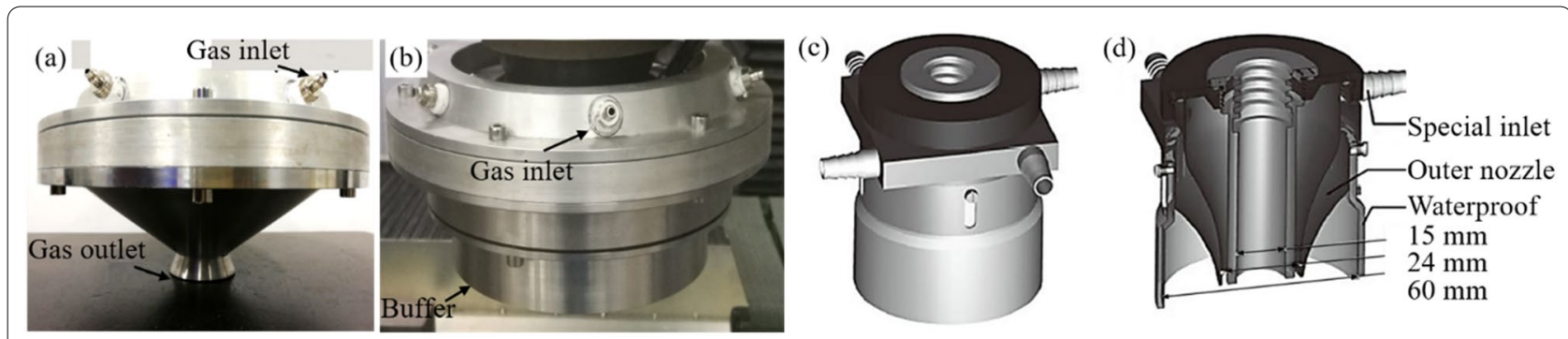

Figure 3 Structure of the (a) first type and (b) second type gas curtain nozzles developed by the author's group in Southeast University in China [29], and (c), (d) 3D schematic of the drainage device with spiral air inlet developed by South China University of Technology in China [30]

stable dry zone can be achieved, and the pressure in the center of the dry zone is lower than that in the surrounding area, which is conducive to reducing the negative impact of water pressure on the arc.

\subsection{Drainage Nozzles with Water Drainage Method}

The flow rate of the drainage gas increases with the water depth to effectively drain the water. The high-pressure gas will affect the morphology of the melt pool and the interaction between laser and feedstock. To overcome the difficulties, the water drainage method is developed when ULBW is employed in deep water environments. In 2001, Hitachi collaborated with Daihen Corp. in Japan developed a water curtain underwater laser torch [31]. Figure 4(a) presents that this water curtain is used in both downward and horizontal directions. A high surface tension and a heavy and viscous film are essential for the formation of a stable gas space upon the $\mathrm{V}$ or $\mathrm{U}$ groove. They claimed that the water curtain nozzle can meet the above mentioned requirements based on a two-phase hydrodynamic analysis and experiments. The water curtain is verified to be very stable because of the water viscosity, water mass and strong surface tensile force. Their results demonstrated that a local dry area with a diameter of $10 \mathrm{~mm}$ or more was essential for real-time monitoring by IR or UV as well as following up $10 \mathrm{~mm}$ deep, single $\mathrm{U}$ or $\mathrm{V}$ grooves. Zhang et al. [32] from Tsinghua University in China designed a water-curtain drainage nozzle (Figure 4(b)) and conducted a detailed study on its drainage effect. Their experimental results showed that the water and gas flow rates determined the stability of the dry zone, and the structure size of the drainage device was closely related to the process window and quality of drainage.

\subsection{Drainage Nozzles with Water \& Gas Hybrid Drainage Method}

The authors' group from Southeast University in China developed one kind of drainage nozzle utilizing the water \& gas hybrid drainage method (Figure 5) based on the

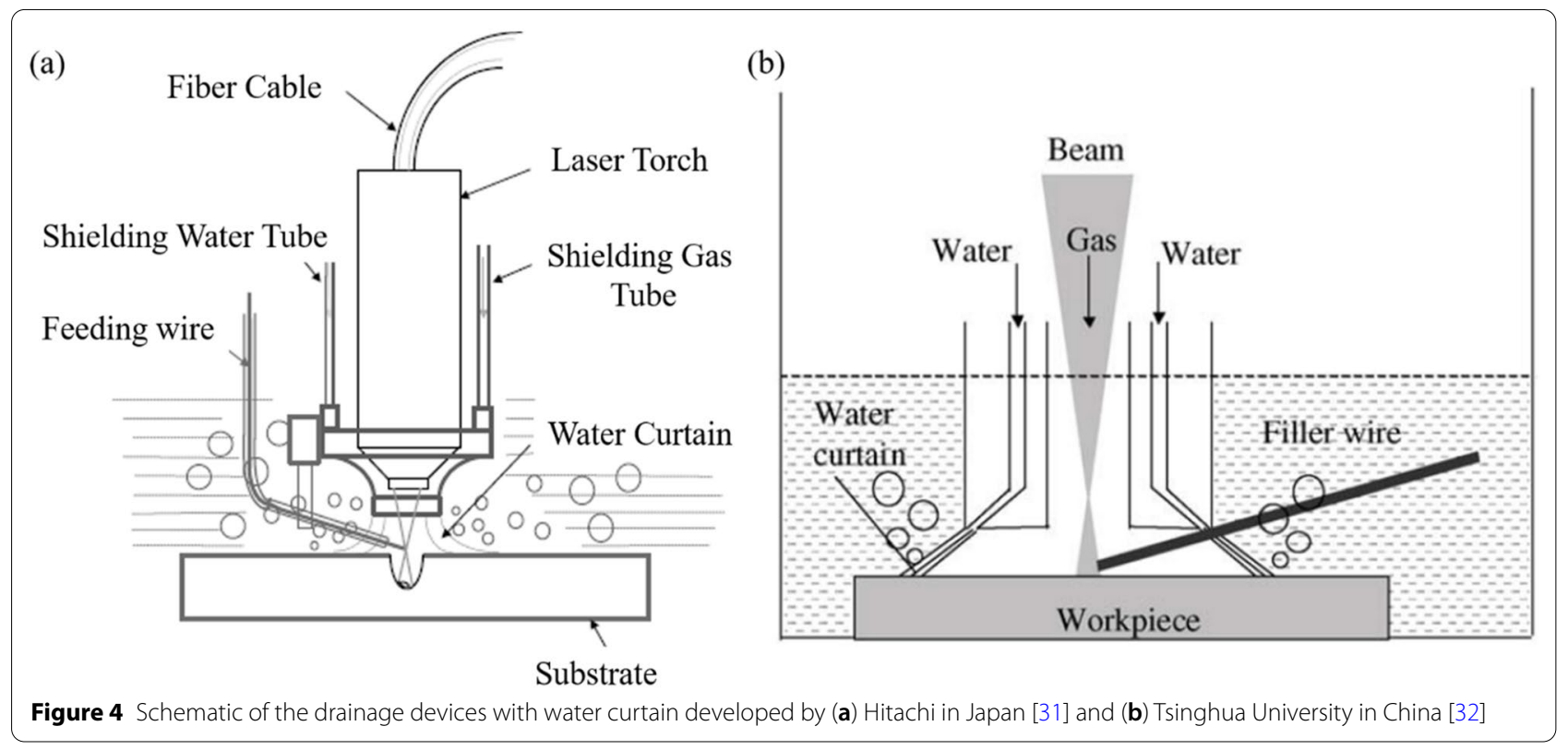




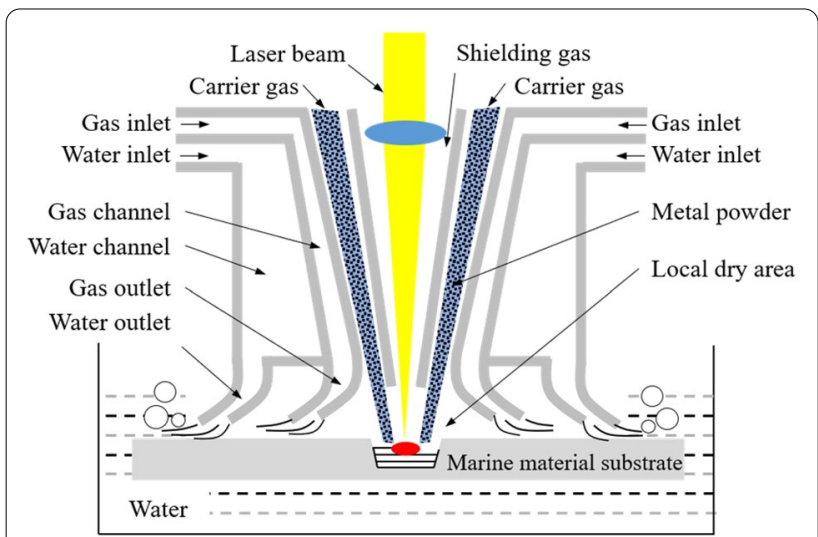

Figure 5 Schematic of the drainage nozzle with water \& gas hybrid drainage method developed by Southeast University in China

previous gas curtain nozzle in Figure 3(b). Water and compressed gas first enter the channels through the water inlets and gas inlets, respectively. Then the water and gas are injected from the outlets, as shown in Figure 5. The air curtain is arranged within the scope of water curtain. The water curtain can promote the stability of the gas curtain because the water curtain can resist the influx of external water from the environment. The advantage of the water \& gas hybrid drainage method is that the stability and dryness of the whole cladding area can be ensured. At the same time, the interaction between the laser and powder is not disturbed.

\subsection{Drainage Nozzles with Multi-function}

In 2009, Toshiba Corporation in Japan developed a multi-function laser welding head (Figure 6(a)) [33]. The dimensions of the developed head height, width and depth are approximately $85 \mathrm{~mm}, 85 \mathrm{~mm}$ and $45 \mathrm{~mm}$, respectively. It is capable to create narrow areas in the reactor components with the help of the developed head which is very compact. The developed head has several functions. It can be used to carry out underwater laser peening as preventive maintenance. It can also be used to perform laser ultrasonic testing and laser welding for inspection, or be used to laser welding for repair [33]. In 2012, Toshiba Corporation developed a ULBW system for reactor vessel nozzles of pressurized-water reactor [34]. The welding machine consists of a welding head and an accessing unit. Figure 6(b) displays the work process for reactor vessel nozzles. First, foreign material exclusion barriers are installed in the back of nozzles. Second, the underwater excavation machine is used to prepare the weld groove. Third, flaw detection inspection is carried out to inspect flaws. Fourth, the welding machine is used to finish the primary water stress corrosion cracking resistant welding. Fifth, the underwater excavation machine is used to finish the surface after welding. Sixth, final acceptance inspection is carried out and the foreign material exclusion barriers are removed finally. This process does not need to seal up and drain the work area in reactor vessel, reducing the work period to less than half of a conventional system which needs draining.

In summary, for underwater laser welding/cladding, the gas drainage method can generate a stable local dry area in shallow water depth (the reported maximum

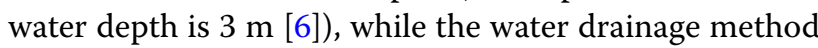
can realize this function at a water depth up to $30 \mathrm{~m}$ [31]. The developed drainage nozzle with hybrid gas and water drainage method is expected to obtain a better drainage quality in a larger water depth. The combination of the gas curtain and water curtain in a single drainage nozzle synergistically benefits the formation of a stable local dry area and overcomes the drawbacks of the gas drainage method. Drainage nozzles with multifunction

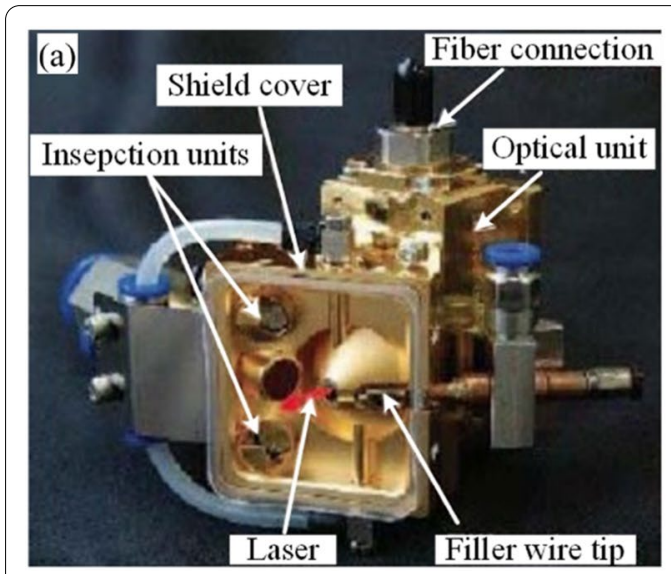

(b)

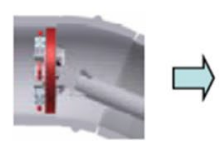

FME barrier installation

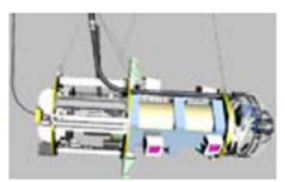

PWSCC resistant welding

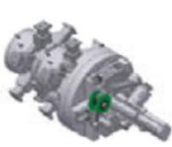

Groove excavation

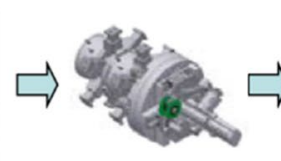

Final contour

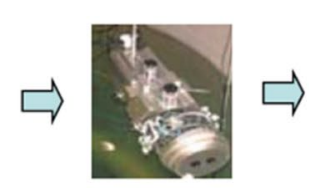

Flaw detection inspection

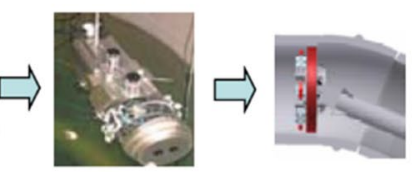

Final acceptance inspection
FME barrier removal

Figure 6 (a) Graph of the multifunction laser welding head [33] and (b) work process for reactor vessel nozzles developed by Toshiba Corporation in Japan [34] 
collaborates inspection, groove excavation with ULBW process to perform the whole work process for repair of reactor vessel nozzles, which realizes the actual application in nuclear power plant equipment.

\section{Underwater Laser Processing} and Microstructural-Mechanical Behavior of Repaired Marine Materials

\subsection{Studies of Underwater Laser Welding/Cladding} Processes Performed in Japan

Due to its relatively small land area and lack of traditional energy materials, Japan is committed to developing wind power, nuclear power and other new energy sources. One third of Japan's electricity supply comes from the nuclear power plants. When the nuclear power plant is approaching the designed service life, it is urgent to maintain the equipment. Therefore, underwater laser welding has been developed along with the underwater repair of nuclear power plant facilities. Basically, stress corrosion cracking on a reactor component has become the greatest threat for the aged reactors in recent years.

In 2001, Hitachi and Daihen Corp. in Japan developed a water-curtain laser torch which successfully realized a stable underwater dry space [31]. They also carried out underwater laser welding for downward and horizontal direction repairs in a $U$ groove by filling welding wire under the pressure condition of $0.3 \mathrm{MPa}$. In 2004, IHI developed a set of laser welding equipment used for the maintenance of nuclear reactors in underwater environments [35]. They manufactured test pieces with SUS304 as the base material and Y308L as the filler solid wire. The results of visual inspection, liquid penetrant test and organization observation are shown in Figure 7(a). The result of the tensile test shows that the strength of the butt joint was higher than the standard value of the base material. The result of the bend test shows that there was no defect in the butt joint after the bending experiment. In 2006, IHI carried out underwater laser welding on Ni-base alloy and stainless clad materials using Nd:YAG laser [8]. To prevent corrosion attack by the service environment, alloy 690 was chosen as weld filler material for a corrosion resistant overlay on 304 stainless steel plates. Figure 7 (b) displays the results of penetration tests and the graphs of bead appearances for each position by underwater laser welding. All the bead appearances for the flat, horizontal, and vertical downward position welding presented metallic brightness. No surface defect was detected except several irregular bead shape areas and craters of each pass. In contrast, the bead surface for vertical upward position welding was oxidized and rough. The main reason is that the solidification area of the welding melt pool was extruded from the dried region

(a)
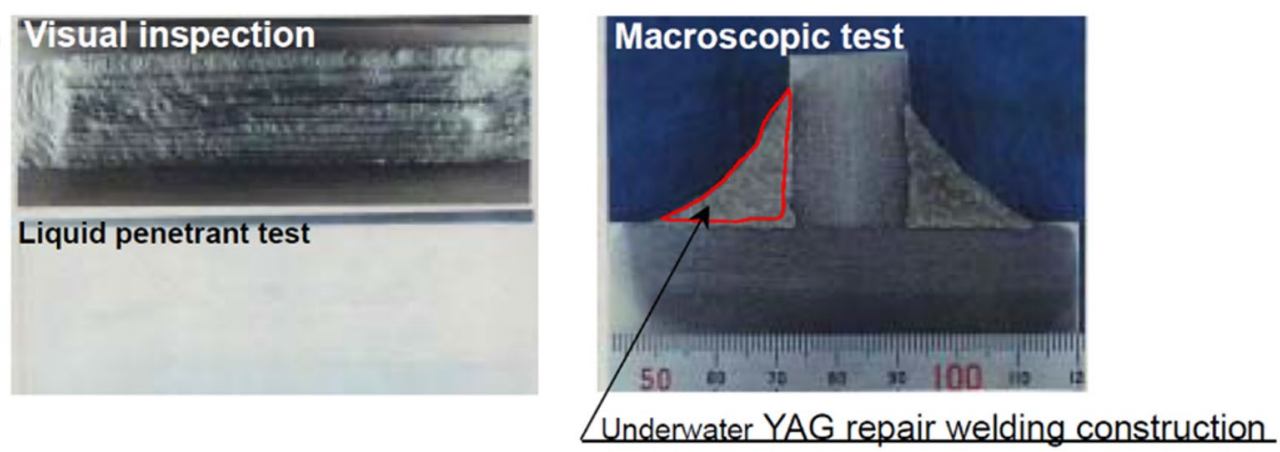

(b)

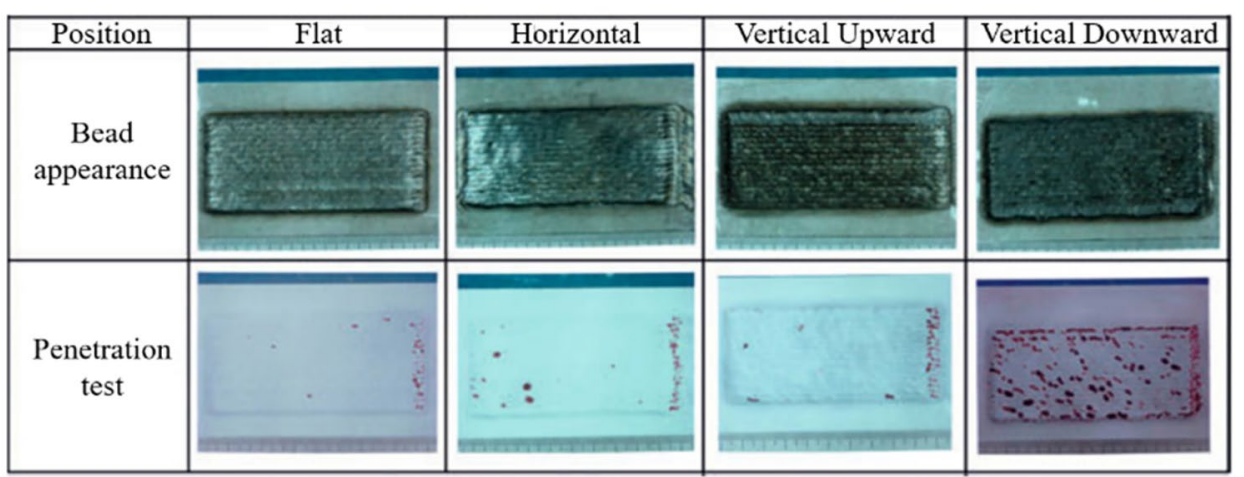

Figure 7 Results from IHI in Japan: (a) Visual inspection, liquid penetrant test and organization observation of Y308L coating by underwater Nd:YAG laser welding [35] and (b) bead appearance and penetration test of underwater Nd:YAG laser cladding for each position [8] 
which was formed by the shielding gas. In addition, to reduce the adverse effects of nuclear radiation in maintenance work and improve the detection and maintenance ability, IHI began to carry out experimental testing of the robot in the tank in 2008, and the results showed that the detection quality and speed of the robot had been greatly improved [36].

In 2004, Toshiba reported several laser-based repair techniques which can be used in the nuclear power plants [37]. They employed laser shock peening technology on reactor components in the boiling-water reactor plants. The results of the laser peening for Alloy 600 and the applicability for bottom-mounted instruments and reactor vessel head of pressurized-water reactor were confirmed by the experimental measurement. They also confirmed that the crack tip could be repaired by underwater laser seal welding technology. The schematic of experimental set for underwater laser seal welding is shown in Figure 8(a). Figure 8(b) presents the welding sequence and the results using a mock-up. It can be seen from Figure $8(\mathrm{~b})$ that the surface of the deposited material presented a metallic color without oxidation. At the same time, a good welding bead could be acquired, which is the same as the flat test piece.

In 2008, Tamura et al. [2] in Toshiba conducted underwater Nd:YAG laser welding of composite materials used in nuclear power plant vessels. They assessed the propensity of composite layers for stress corrosion cracking. The results show that when the filler metal with high $\mathrm{Cr}$ content was directly fused to the base metal with high sulfur content, sulfur transferred from the base metal to the cladding metal, resulting in many tiny cracks in the cladding layer. Adding a layer of Y309L between the stainless steel base material and ERNiCrFe-7A cladding metal as the barrier layer can effectively prevent the sulfur element in the base material from diffusing to the cladding metal, which helps to obtain a cladding layer without defects and with a better corrosion resistance.

In 2009, Hino et al. [21] in Toshiba conducted laser beam welding and underwater laser cladding experiments. 304 stainless steel and alloy 600 were used as the base material. The sulfur content of 304 stainless steel was $0.029 \%$. Two filler metals, ERNiCrFe-7A and ERNi$\mathrm{CrFe}-7$ were evaluated in their study. The experimental condition is shown in Table 1. The ERNiCrFe-7A is a modified alloy of ERNiCrFe-7 to reduce the rate of ductility dip cracking. The deposition rate of ERNiCrFe-7 on Alloy 600 is $22 \mathrm{~mm}^{3} / \mathrm{s}$.

Figure 9(a)-(c) show the typical cross-sectional micrograph welded at different deposition rates. The experimental results showed that both cladding materials could obtain good macroscopic morphology. No cracks or other defects were found in the microscopic structure detection. Some of the US old nuclear plants employed high $S$ stainless steel. When ERNiCrFe-7A was directly cladded on the high $\mathrm{S}$ stainless steel, several cracks were formed in the cladded material, as shown in Figure 9(d). It suggests that the element $\mathrm{S}$ moved from the high $\mathrm{S}$ stainless steel to the cladded material. When Y309L barrier layer

Table 1 Experimental conditions of the underwater laser beam welding [21]

\begin{tabular}{llll}
\hline Step & Base metal & Filler metal & Deposition rate \\
\hline 1 & Alloy 600 weld metal & ERNiCrFe-7 & Low \\
2 & Alloy 600 weld metal & ERNiCrFe-7 & High \\
3 & Alloy 600 weld metal & ERNiCrFe-7A & High \\
4 & Type 304 stainless & Y309L (buttered layer) & High \\
& steel (Sulfur content & ERNiCrFe-7A (outer & \\
& $0.029 \%)$ & layer) & \\
& & &
\end{tabular}
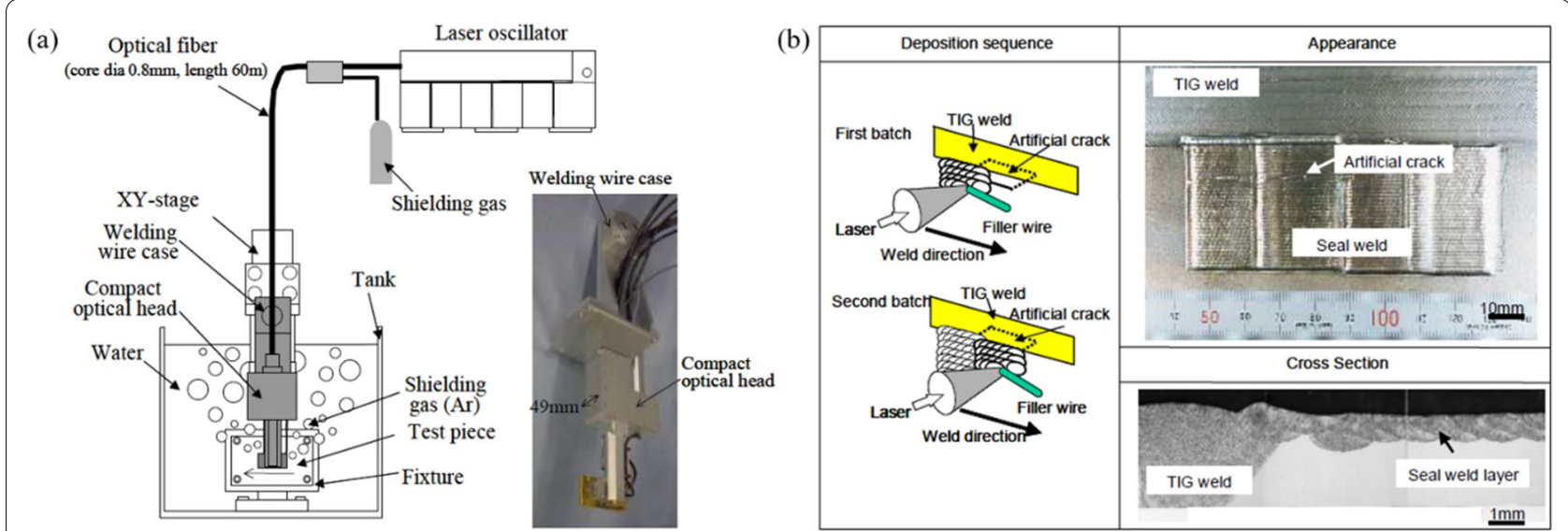

Figure 8 Results from Toshiba in Japan: (a) Schematic of experimental setup for laser seal welding and (b) deposition sequence and result of mock-up test of laser seal welded 304L stainless steel [37] 


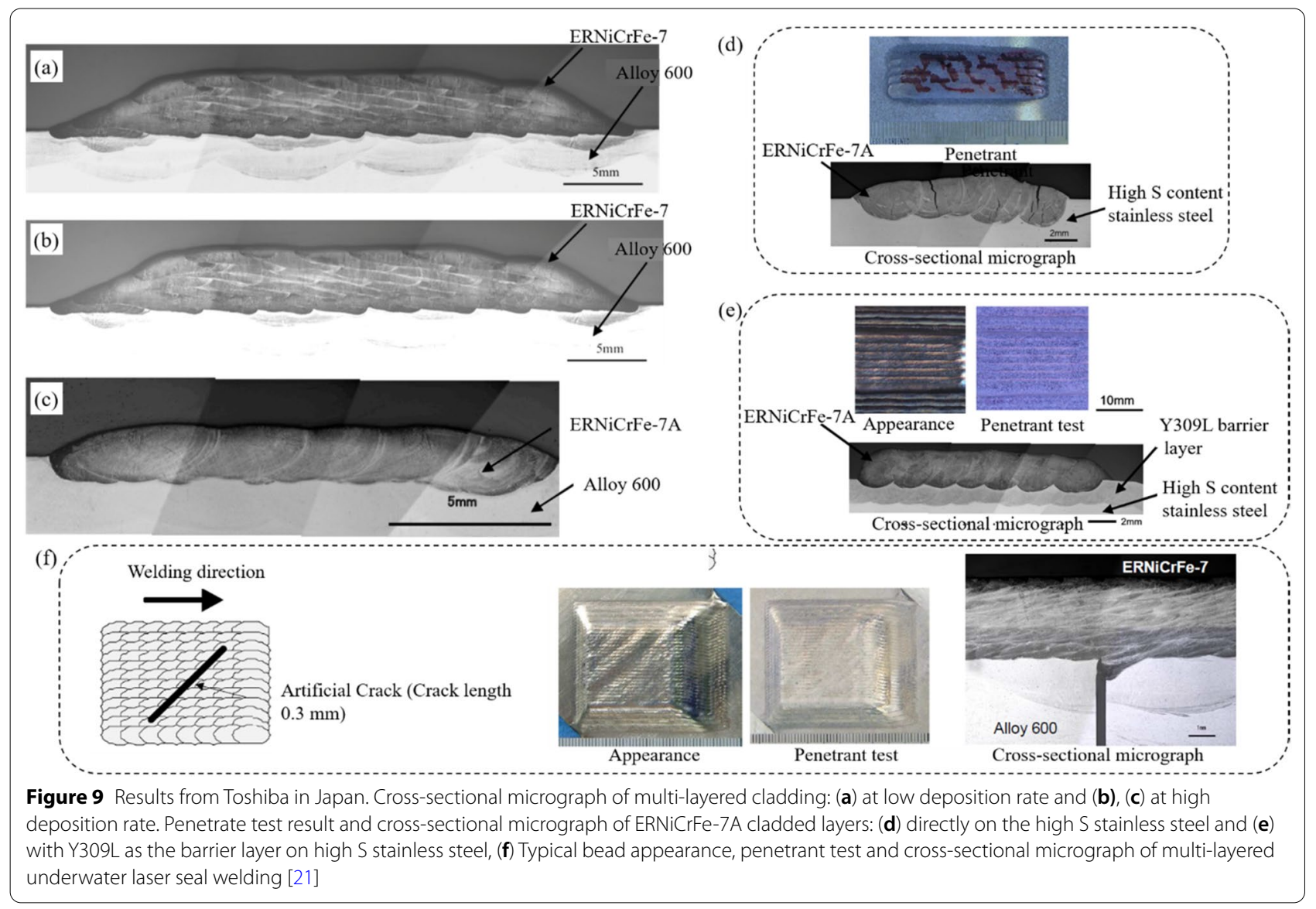

was cladded previous to the ERNiCrFe-7A cladded layer, there were no cracks in the cladded layer. The results indicated that the initiation of cracks can be effectively decreased by the insertion of barrier layer, as shown in Figure 9(e). Figure 9(f) presents a typical bead appearance and penetrant test results as well as the cross-sectional micrograph of multi-layered underwater laser seal welding to isolate stress corrosion cracks from corrosion environment. Underwater seal welding was conducted on a specimen with an artificial crack on the top surface. Defects such as porosity, undercut and cracks were not observed. It can be claimed that the cracks can be sealed by underwater laser seal welding and the cracks can be isolated from the water environment after repairing.

\subsection{Studies of Underwater Laser Welding/Cladding Processes Performed in the United States}

In 2009, Westinghouse Electric Company (WEC) and Electric Power Research Institute (EPRI) in the United States conducted a collaborative study in which the underwater laser welding technology was used to repair cracks. In 2010, the American Welding and Repair Technology Center developed laser underwater welding technology to solve the repair problems within the limited accessibility of nuclear power plant vessels, pipelines, etc. [3]. Bucurel et al. [38] studied the effect of underwater YAG laser welding process on the structural mechanical properties and material properties. A three-layer Alloy 52MS was deposited on a low-alloy steel substrate. It is observed that the mechanical properties obtained from single-side bending and all-weld-metal tensile tests, as well as the material properties such as diffused hydrogen and $\delta$ ferrite content were not affected by the underwater welding. Meanwhile, the Charpy impact and hardness tests showed that the heat-affected zone had a tempering effect during the underwater laser welding process, which was favorable for the laser beam welding repair. The side-band test sample, all-weld-metal tensile samples and the microstructure of the three-layer coating are shown in Figure 10(a)-(c), respectively.

\subsection{Studies of Underwater Laser Welding/Cladding Processes Performed in China}

In 2004, Zhang et al. [39] from Tsinghua University in China investigated the relationship between the weld quality and optical emissions during the underwater 

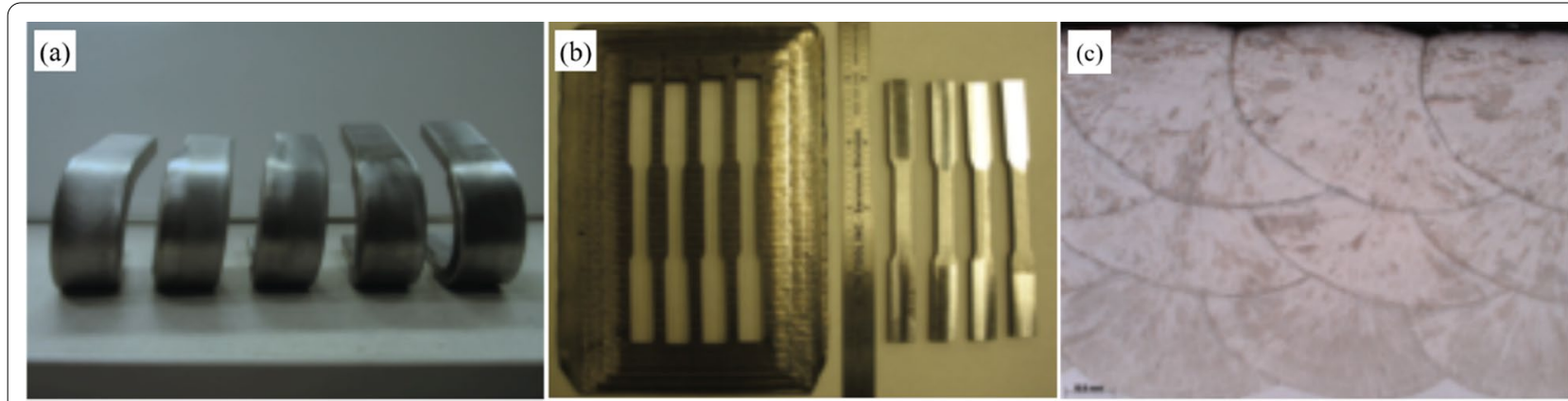

Figure 10 (a) Side-bend test samples, (b) all-weld-metal tensile samples and (c) three-layer ER308L weld on 304L SS plate using the underwater laser beam welding technique [38]

Nd:YAG laser beam welding. To detect the ultraviolet and infrared waveband of the optical emissions generated during the welding process, they set up a sensing system which contained two optical sensors. They proved that a local dry area was necessary for the successful execution of ULBW. The signal stability can be used to determine the best shielding condition needed for ULBW. In 2006, Zhang et al. [32] investigated the influence of the shielding conditions of the local dry area on the weld quality of 304 stainless steel by underwater Nd:YAG laser welding. They concluded that the maximum water depth that deep penetration welding can be performed was approximately $2 \mathrm{~mm}$. Therefore, if the water depth is beyond this value, a local dry area is essential. When the welding parameters are determined, the welding quality of ULBW is primarily decided by the shielding conditions of the underwater local dry area. Sound weld quality without any porosity and surface defects can be obtained in
ULBW under good shielding conditions. Figure 11 shows the influence of gas flow rate on the weld width and penetration depth when the water flow rate is constant [32]. The penetration depth tended to decrease with the increase in gas flow rate. The value of penetration depth did not vary much comparing with that in air at the same gas flow rate. In contrast, the width of weld bead tended to become large with the increase in gas flow rate.

From 2017 to 2020, Harbin Institute of Technology in China reported the investigation on underwater laser welding [5, 20, 24]. In 2017, Guo et al. [24] investigated the influence of water depth $(0-8 \mathrm{~mm})$ on the welding process and welding quality of 304 stainless steel by underwater fiber laser welding. It is observed that when the thickness of water layer in the laser welding zone was less than $3 \mathrm{~mm}$, water had a slight effect on the ULBW. They claimed that it might not be necessary to drain the water completely around the welding zone. However,

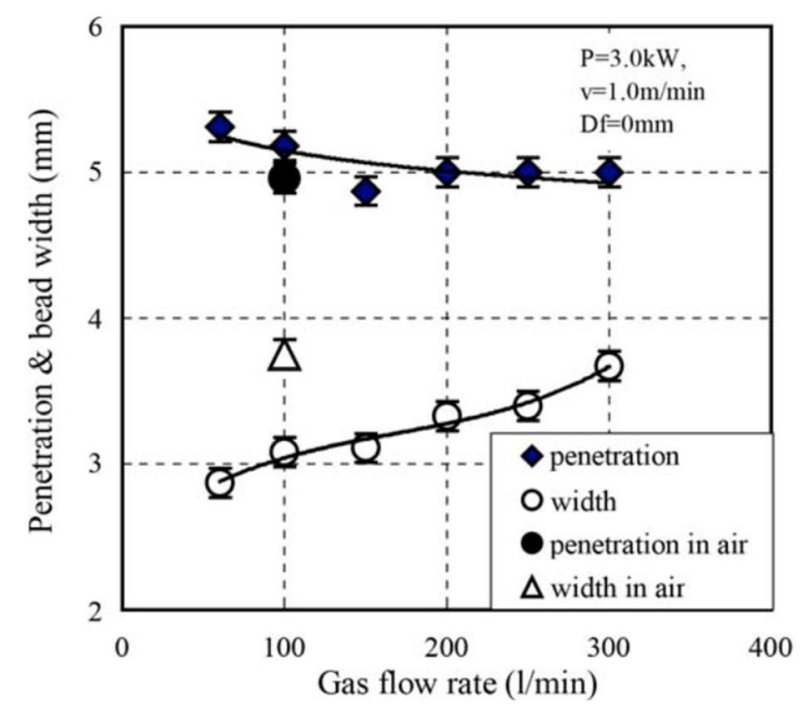

\begin{tabular}{|c|c|}
\hline Gas flow & Cross section \\
\hline $\begin{array}{c}100 \\
\text { (in air) }\end{array}$ & \\
\hline 60 & \\
\hline 150 & \\
\hline 250 & \\
\hline
\end{tabular}

Figure 11 Penetration depth and weld bead width as the function of gas flow rate when the water flow rate is constant [32] 
when the thickness of water layer in the laser welding zone was larger than $7 \mathrm{~mm}$, water showed a strong hindering effect on the laser beam. In 2018, Guo et al. [20] reported the results of 304 stainless steel by ULBW with a double-layer gas curtain nozzle. They focused on the relationship between the gas rates and the shielding condition at a water depth of $120 \mathrm{~mm}$. The high-quality butt joint without welding pores was fabricated under optimal process parameters. The impact toughness and tensile strength of the ULBW welded joints were almost the same as those of the in-air welded joints. The influence of welding speed on the macro cross-section and welded joints appearance of butt joints is shown in Figure 12. It can be seen from Figure 12 that all the tested welding speeds can lead to the complete penetration. When the welding speed was $1.0 \mathrm{~m} / \mathrm{min}$, no welding porosity or cracks was detected. In 2020, Guo et al. [40] reported the microstructure and properties of Ti-6Al-4V titanium alloy by underwater laser welding at a water depth of 60 $\mathrm{mm}$. A double-side gas-shielding nozzle was utilized to perform the underwater laser welding. The defocus distance and heat input were optimized by analyzing the weld quality. They stated that when the laser beam was focused on the upper surface, excellent impact toughness and tensile strength can be obtained. The values of tensile strength and impact toughness of the joint by ULBW were approximately $90 \%$ of the values for the joint by inair laser beam welding.

In 2020 and 2021, Fu et al. [41-43] from Harbin Institute of Technology in China reported the fabrication of Ti-6Al-4V alloy by wire-based underwater laser cladding technique at a water depth of $60 \mathrm{~mm}$. Figure 13(a), (b) display the cladding layers of Ti-6Al-4V alloy prepared in underwater and in-air environments [41]. There were several long cracks and spatters distributed on the cladding layer surface. They stated that the water fast cooling rate during underwater laser cladding contributed to the increase in the amount of $\alpha^{\prime}$ and the decrease in the thickness and the grain size of $\alpha$ microstructure. Additionally, Fu et al. [42] investigated the influence of gas flow rate on

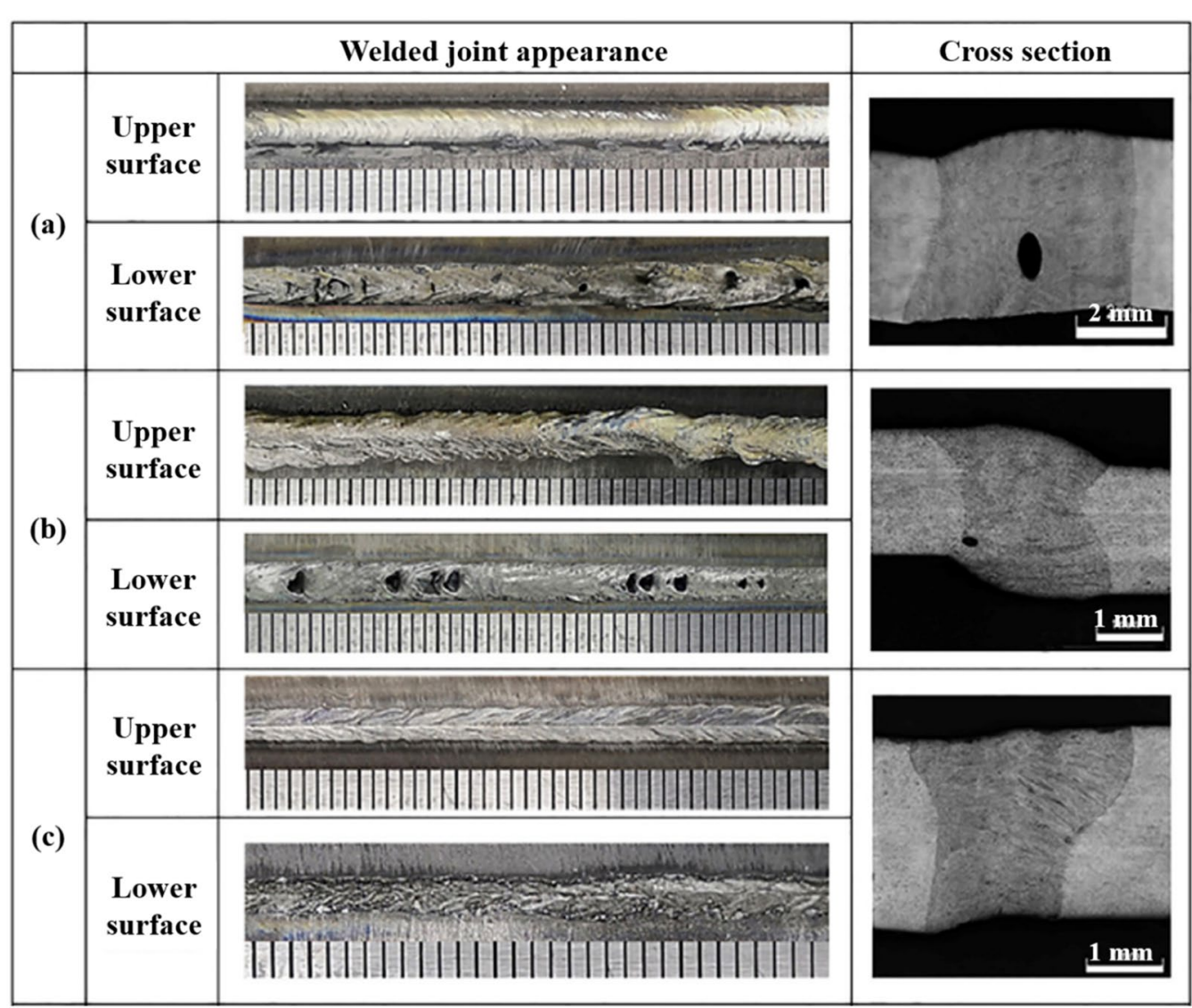

Figure 12 Welded joint appearance and cross section of butt joints of 304 stainless steel at different welding speeds: (a) $0.6 \mathrm{~m} / \mathrm{min}$, (b) $0.8 \mathrm{~m} / \mathrm{min}$, (c) $1.0 \mathrm{~m} / \mathrm{min}[20]$ 

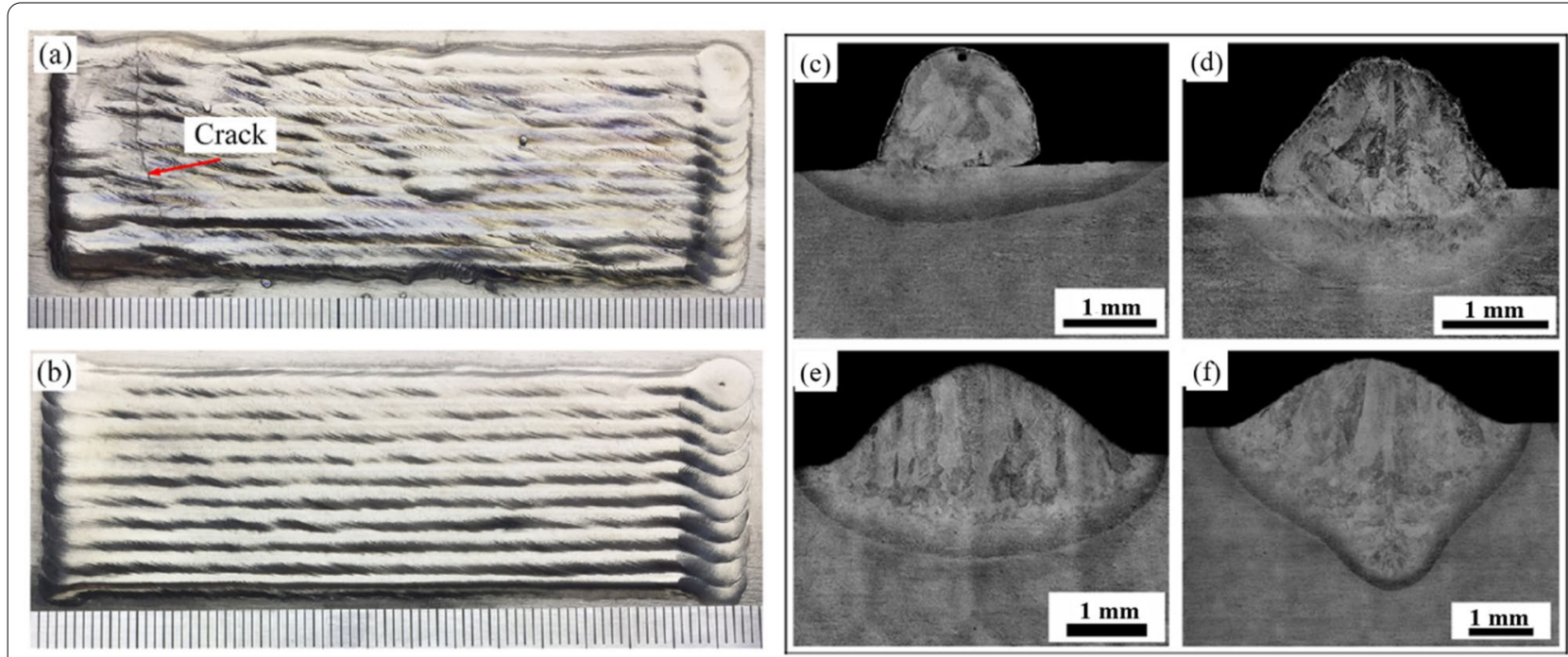

Figure 13 Wire-based laser cladding layers of Ti-6Al-4V in (a) underwater and (b) in-air environment [41]; Cross sections of the single track Ti-6Al-4V deposited in underwater and in air environments: (c) $10 \mathrm{~L} / \mathrm{min}$, (d) $18 \mathrm{~L} / \mathrm{min}$, (e) $20 \mathrm{~L} / \mathrm{min}$, (f) in-air environment [42]

geometry characteristics, cladding appearances, microstructural features and mechanical properties of deposited tracks. Figure 13(c)-(f) show the cross sections of the single track which were built in underwater and air environments. When the gas flow rate increased to $20 \mathrm{~L} / \mathrm{min}$ (Figure 13(e)), the interface and macroscopic pores in the as-deposited Ti-6Al-4V disappeared. The results demonstrated that sound metallurgical bonding can be obtained by the underwater laser cladding technique. In addition, $\mathrm{Fu}$ et al. [43] reported the fabrication of thin-walled Ti-6Al$4 \mathrm{~V}$ deposits by underwater laser cladding technique. The protection effect of the nozzle played a key role in deciding the deposition appearance. The microstructural evolution and grain growth of the as-built Ti-6Al-4V were studied in detail in the literature [43].

In 2021, Fu et al. [44] reported the results of the 304 stainless steel by underwater laser cladding technique at a water depth of $60 \mathrm{~mm}$. The laser cladded coating was porosity and crack free. Solidification mode slightly changed due to the high cooling rate in the underwater environment. Figure 14 presents the graphs of cladded samples by underwater laser cladding technique and in-air laser cladding technique. It can be seen from Figure 14(c) that gaps distribute between the adjacent cladding tracks and the surface of cladding zone is uneven. In contrast, for the in-air laser cladding coating (Figure 14(b)), the surface is uniform and flat. In addition, there is no gap generated at the interface between the adjacent cladding tracks, as shown in Figure 14(b).

\subsection{Studies of Underwater Laser Direct Metal Deposition Developed by Southeast University in China \\ 3.4.1 Comparison Investigation of the Differences between the Convection, Conduction and the Metallurgical Kinetics in the Melt Pool during ULDMD and DMD}

The authors' group from Southeast University in China has been committed to the development of the new technique, namely powder-feeding based underwater laser direct metal deposition (ULDMD) for more than five years. They have developed three types of drainage nozzles since 2016 [29, 45], as shown in Figure 3(a), (b) and Figure 5. In 2021, they reported the investigation on Ti-6Al-4V blocks fabricated by ULDMD at a water depth of $55 \mathrm{~mm}$ [45]. Figure 15(a) shows the deposit appearance of the ULDMD Ti-6Al-4V blocks. The top surface of the sample fabricated by powder-feed ULDMD is relatively smooth compared with that fabricated by wire-feed ULDMD (Figure 13(a)). Previous studies on ULDMD reported the microstructure and mechanical properties of the ULDMD materials [21, 39, 42-44]. However, how the underwater environment affects the convection, conduction and the metallurgical kinetics in the melt pool during ULDMD has not been illustrated, which has a decisive effect on the microstructure and mechanical properties of the samples fabricated by ULDMD.

Figure 15(b), (c) compare the thermal boundary conditions for the deposition of Ti-6Al-4V by in-air laser direct 


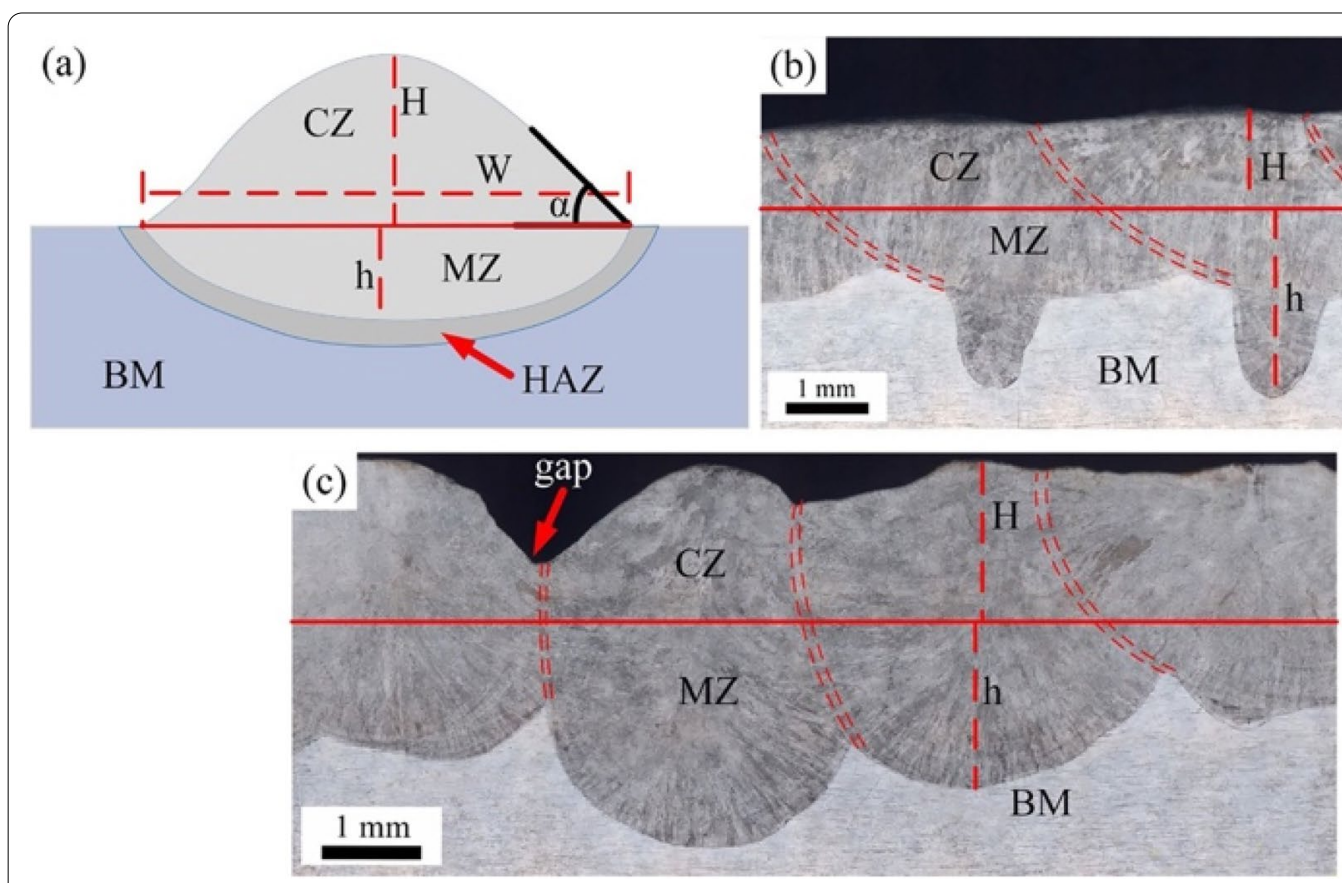

Figure 14 The macro-morphology of the transverse section: (a) diagram, (b) in-air laser cladding coating, (c) underwater laser cladding coating of 304 stainless steel [44]
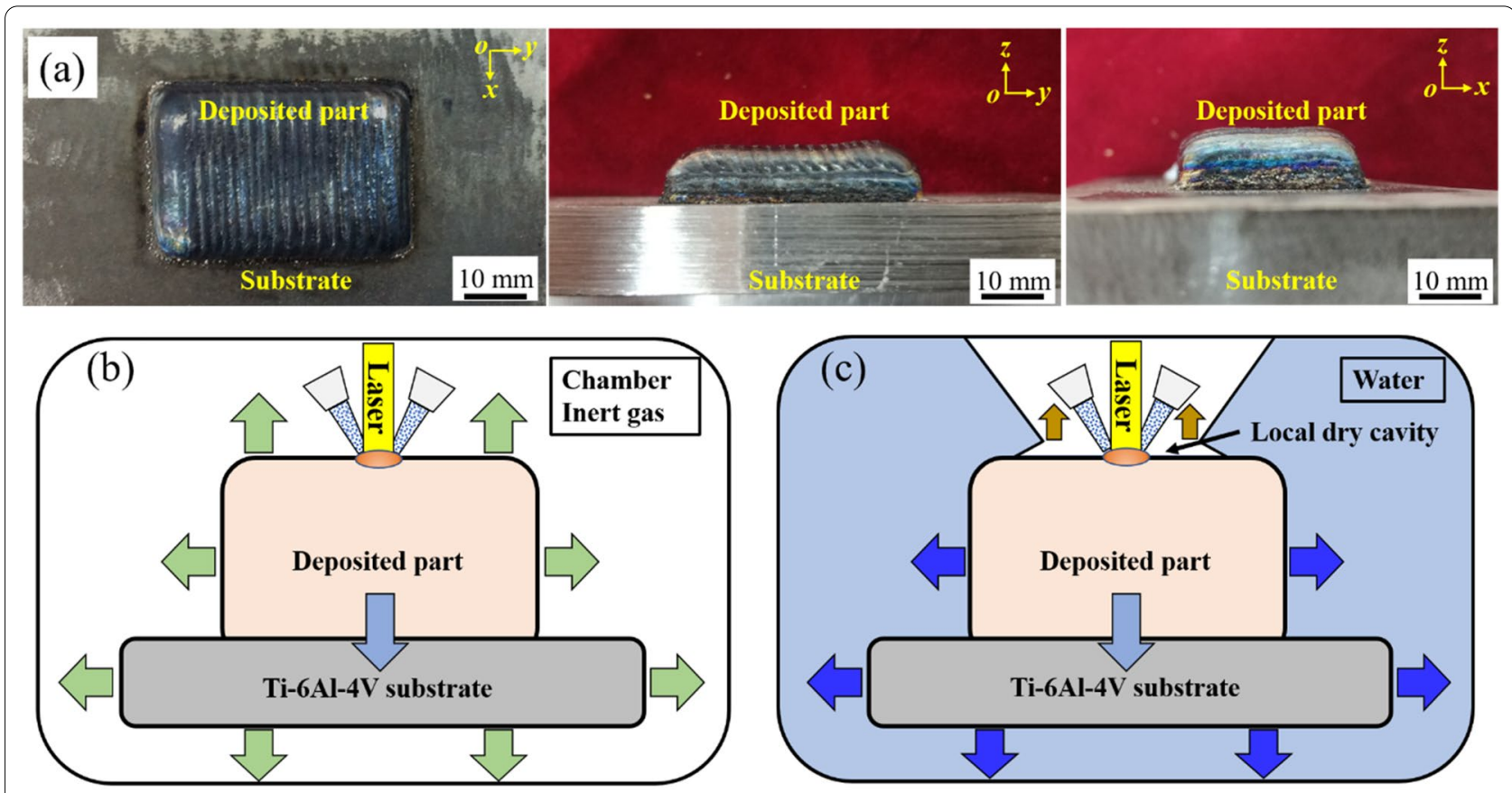

Heat conduction $q_{\text {cond }}$

Gas natural convection + Radiation $q_{\text {conv-a }}+q_{\text {rad }}$

Gas forced convection + Radiation $q_{\text {conv }-f}+q_{\text {rad }}$

Water natural convection + Radiation $\boldsymbol{q}_{\text {conv-w }}+\boldsymbol{q}_{\text {rad }}$

Figure 15 (a) Morphology of the ULDMD Ti-6Al-4V blocks and thermal boundary conditions for the (b) in-air DMD and (c) ULDMD (The arrows with different colors represent the modes of heat transfer) [45] 
metal deposition (DMD) and ULDMD, respectively [45]. The presence of water and forced gas contributed to the rapid cooling of the deposited part due to the large heat convection coefficient of the water and forced gas. As a consequence, the ULDMD samples had a fast cooling rate and steep temperature gradient in the melt pool zone during the underwater deposition process. For the sample by in-air DMD, the heat convection coefficient of gas was small and the main mode of heat dissipation was the heat conduction between the as-deposited layers and Ti-6Al-4V substrate. As a result, the temperature of the deposited part and substrate would continue to increase during the in-air DMD process. As a result, the cooling rate and temperature gradient of the melt pool zone were expected to decrease with the increase of deposition height. The differences of the thermal histories contributed to the differences of thermodynamics, thermomechanical, microstructural evolution and the resultant mechanical properties.

In addition, a comparative study was carried out to investigate the differences of temperature histories, phase transformation and metallurgical kinetics in the melt pools during ULDMD and in-air DMD for the repair of HSLA-100 steel at the water depth from 20 $\mathrm{mm}$ to $150 \mathrm{~mm}$ [46]. Figure 16(a), (b) show the thermal histories in different positions of thermocouples obtained by experiment and simulation. For thermocouple $\mathrm{B}$, the temperature of the substrate increased continuously (maximum $193{ }^{\circ} \mathrm{C}$ ) during the entire inair DMD process. However, the underwater substrate and deposits were cooled below $100{ }^{\circ} \mathrm{C}$ after each layer because of the forced cooling effect by water. This difference was clearly presented in the position of thermocouple A which was close to the repair zone (maximum $306{ }^{\circ} \mathrm{C}$ in air compared with that of $120{ }^{\circ} \mathrm{C}$ in water), as shown in Figure 16(b). When in-air DMD was introduced into an underwater environment, the heat dissipation rate in the as-deposited parts increased notably during ULDMD. Figure 16(c), (d) present that the dimensions of the ULDMD melt pool are smaller than those of the DMD melt pool. Furthermore, the peak temperature of the ULDMD melt pool $\left(2580{ }^{\circ} \mathrm{C}\right)$ was lower than that of the DMD melt pool $\left(2688^{\circ} \mathrm{C}\right)$. Figure 16(e), (f) schematically show the microstructural evolution of HSLA-100 steel during ULDMD and inair DMD. The thermodynamically governed dislocation evolution and phase precipitation process and the relationship between activation energy and as-deposited microstructure were different in the ULDMD process from those in DMD process. The columnar austenite in the ULDMD samples experienced rapid cooling and transformed into fine martensite owing to the water quenching effect, according to the CCT diagram in Figure $16(\mathrm{~g})$. The cooling rates of the subsequent layers were also high enough to promote the formation of lath martensite [46].

\subsubsection{Comparison of Mechanical Properties of Samples Prepared by ULDMD and in-air DMD}

The comprehensive mechanical properties of ULDMD samples and their in-air DMD counterparts are summarized in Table 2. As for the mechanical properties of $316 \mathrm{~L}$ stainless steel repaired in air and water $(100 \mathrm{~mm})$ environments, yield strength, ultimate tensile strength and elongation were approximately the same, as shown in Table 2. However, the impact toughness at $-40{ }^{\circ} \mathrm{C}$ of the $316 \mathrm{~L}$ stainless steel repaired in air $(130 \pm 1 \mathrm{~J})$ and underwater environments $(140 \pm 2 \mathrm{~J})$ decreased dramatically compared with those of the substrate $(238 \pm 2 \mathrm{~J})$. In addition, the tensile strength $(778 \mathrm{MPa})$ and impact toughness $(40 \pm 4 \mathrm{~J})$ of the HSLA-100 samples repaired by ULDMD at a water depth of $150 \mathrm{~mm}$ were comparable to those (785 $\mathrm{MPa}$ and $47 \pm 4 \mathrm{~J}$, respectively) repaired by in-air DMD [46]. However, the mechanical properties of the HSLA-100 steel (645 MPa and 30 $\pm 7 \mathrm{~J}$ ) repaired by ULDMD at a water depth of $1 \mathrm{~m}$ decreased compared with those repaired by ULDMD at a water depth of $150 \mathrm{~mm}$. The reason is that for the HSLA-100 steel repaired at the water depth of $1 \mathrm{~m}$, there are some pores in the repaired zone. Those pores can deteriorate the mechanical strength. The unstable local dry area during underwater manufacturing process resulted in the formation of pores in the repaired zone.

As for Ti-6Al-4V titanium alloy, the ultimate tensile strength of the samples repaired by ULDMD was larger than that of the substrate [49], as shown in Table 2 . However, the yield strength, elongation and impact toughness at room temperature decreased compared with those of the substrate. For the block samples manufactured by ULDMD at a water depth of $55 \mathrm{~mm}$ [45], the specimen extracted from the bottom region of the as-deposited block presented the best comprehensive mechanical properties (good properties in both strength and ductility) with a high strength ( $>900$ $\mathrm{MPa})$ and large elongation to failure ( $>8 \%$; Standard ASTM F1108 [50]). According to the abovementioned mechanical properties of marine metal materials, strength, and ductility of the ULDMD samples are comparable to those of in-air DMD counterparts when a stable local dry area can be successfully created during underwater manufacturing process. 


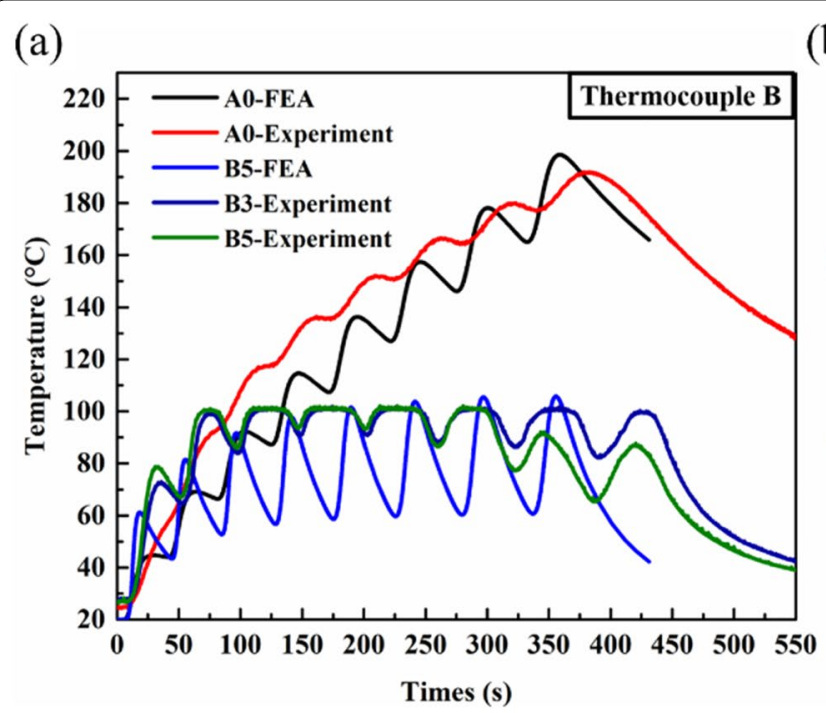

(c)

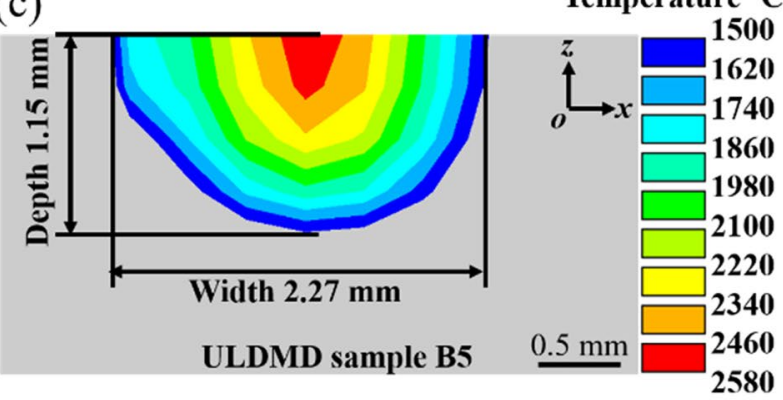

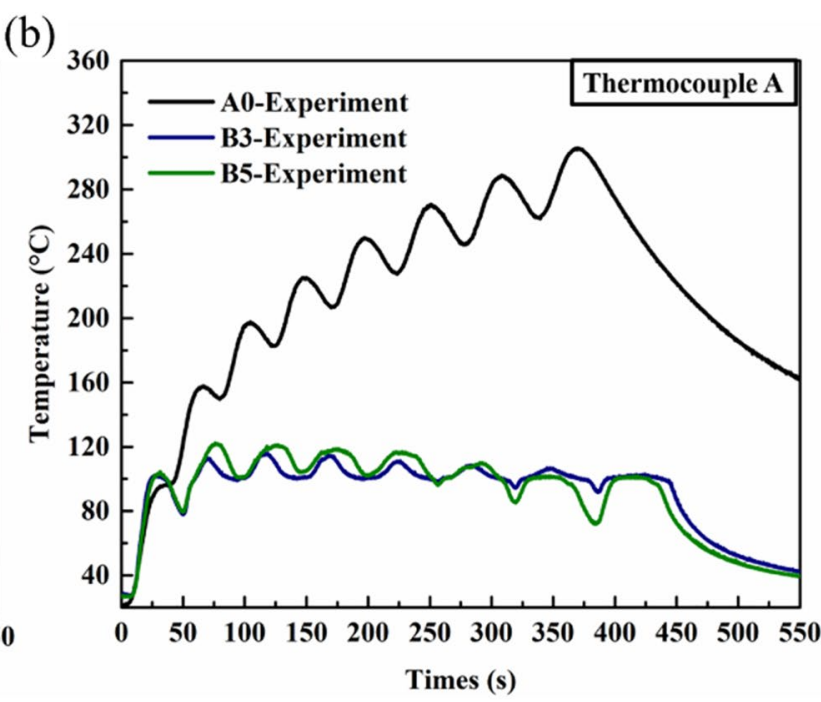

(b)

(d)

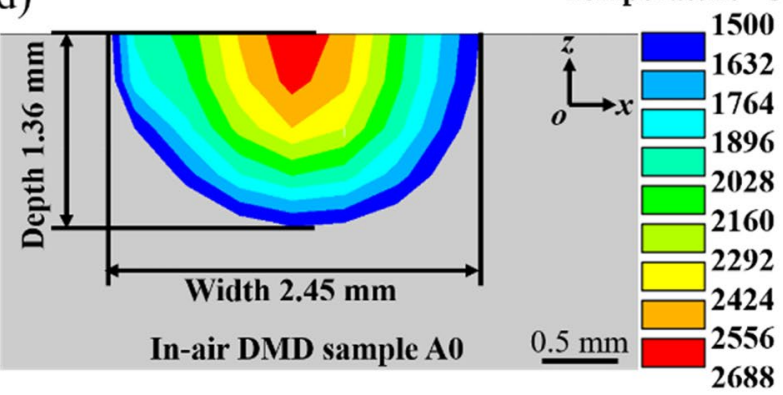

(e) ULDMD sample B5

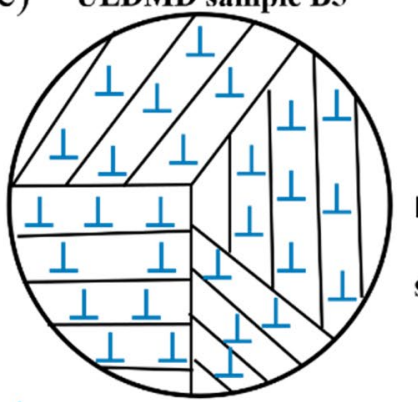

(f) In-air DMD sample A0

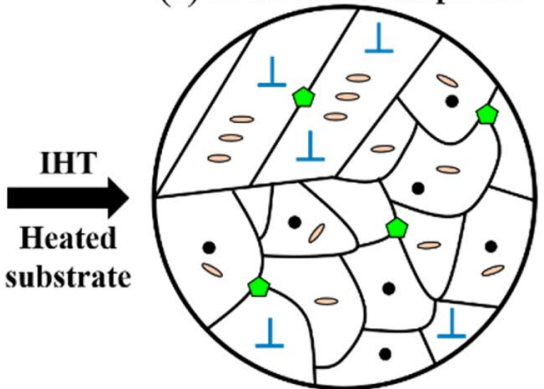

(g)

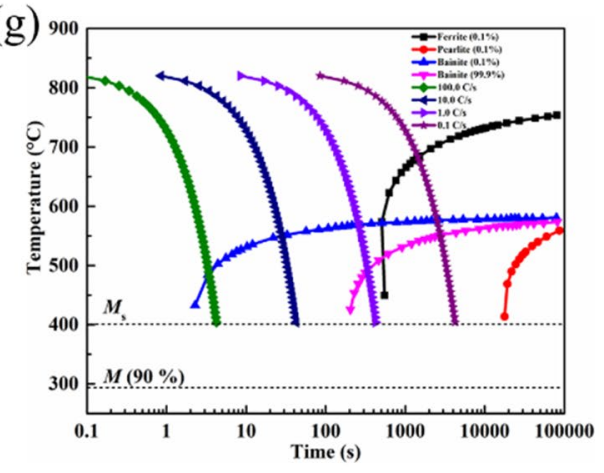

$\perp$ Dislocation $\bullet$ Carbide precipitation $\bigcirc$ E-Cu precipitation $\triangle \mathbf{M}_{23} \mathbf{C}_{6}$

Figure 16 (a) Thermal cycles in position of thermocouple B (20 mm to the center of the trapezoidal groove) by experiment and simulation and (b) comparison of thermal cycles measured by thermocouple A (10 $\mathrm{mm}$ to the center of the trapezoidal groove) during ULDMD and in-air DMD, (c) Temperature contours of melt pool in ULDMD and (d) temperature contours of melt pool in DMD, Schematic illustration of microstructural evolution in (e) ULDMD and (f) in-air DMD processes and (g) CCT diagram for HSLA-100 steel [46]

\subsubsection{Comparison of Diffusible Hydrogen Content of Samples Prepared by ULDMD and in-air DMD}

When the in-air welding/cladding process is transferred to the underwater environment, the risk of cold-cracks induced by diffusible hydrogen would increase [52, 53]. As mentioned before, the underwater dry welding is carried out in a large dry chamber. Disadvantageous effects of water can be eliminated because the filled gas can exhaust the water in the chamber [12]. However, for the underwater wet welding and underwater local dry welding/cladding, the water vapor which surrounds the melt pool can contribute to a high diffusible hydrogen content in the deposited metal. In addition, the fast cooling rate of the deposited metal might trap a number of diffusible hydrogen [54]. Generally, hydrogen cracking occurs as the following three factors appear at the same time [55]: 
Table 2 Summary of mechanical properties of samples by ULDMD and in-air DMD (YS: Yield strength, UTS: Ultimate tensile strength, EL: Elongation and RT: Room temperature)

\begin{tabular}{|c|c|c|c|c|c|c|}
\hline Material & Processing condition & YS (MPa) & UTS (MPa) & EL (\%) & $\begin{array}{l}\text { Impact toughness at } \\
-40^{\circ} \mathrm{C}(\mathrm{J})\end{array}$ & Ref. \\
\hline \multirow[t]{3}{*}{316 LSS } & Substrate & 240 & 582 & 58 & $238 \pm 2$ & [47] \\
\hline & In-air (Repair) & 270 & 584 & 68 & $130 \pm 1$ & [47] \\
\hline & Water depth: 0.1 m (Repair) & 262 & 590 & 70 & $140 \pm 2$ & * \\
\hline \multirow[t]{4}{*}{ HSLA-100 } & Substrate & 778 & 831 & 28 & 165 & [48] \\
\hline & In-air (Repair) & 785 & 831 & 22 & $47 \pm 5$ & [48] \\
\hline & Water depth: 0.15 m (Repair) & 778 & 826 & 22 & $40 \pm 4$ & [46] \\
\hline & Water depth: 1 m (Repair) & 645 & 715 & 12 & $30 \pm 7$ & $*$ \\
\hline \multirow[t]{5}{*}{ Ti-6Al-4V } & Substrate & $932 \pm 4$ & $976 \pm 8$ & $13 \pm 0.7$ & $16(\mathrm{RT})$ & [45] \\
\hline & Water depth: 0.06 m (Repair) & 848 & 1029 & 5.2 & $14(\mathrm{RT})$ & [49] \\
\hline & Water depth: 0.055 mm (Block) & $902 \pm 14$ & $997 \pm 13$ & $8.3 \pm 1.6$ & - & [45] \\
\hline & As cast (ASTM F1 108) & 758 & 860 & 8 & - & {$[50]$} \\
\hline & As wrought (AMS 4928R) & 827 & 896 & 10 & - & [51] \\
\hline
\end{tabular}

Note: The symbol * represents that the data were obtained by the authors

Table 3 Summary of diffusible hydrogen content in samples prepared by underwater laser/arc welding/cladding techniques

\begin{tabular}{|c|c|c|c|c|}
\hline Material & Processing condition & Water depth $(\mathrm{m})$ & $\begin{array}{l}\text { Hydrogen content } \\
(\mathrm{mL} / 100 \mathrm{~g})\end{array}$ & Ref. \\
\hline \multirow[t]{2}{*}{316 LS } & Repaired by In-air DMD & 0 & 1.286 & * \\
\hline & Repaired by ULDMD & 1 & 2.051 & * \\
\hline \multirow[t]{4}{*}{ HSLA-100 } & Repaired by ULDMD & 0.02 & 0.562 & [46] \\
\hline & Repaired by ULDMD & 0.08 & 0.337 & [46] \\
\hline & Repaired by ULDMD & 0.15 & 0.618 & [46] \\
\hline & Repaired by ULDMD & 1 & 1.685 & * \\
\hline ER308L & Underwater local dry laser cladding & - & 0.5 & [38] \\
\hline HSLA S355 & Underwater local dry arc welding & - & $5-21$ & [52] \\
\hline S235JRG2 & Underwater wet welding & - & $45.90-87.40$ & [56] \\
\hline S235JR & Underwater wet welding & 0.2 & $25.85-44.12$ & [57] \\
\hline E40 & Underwater wet welding & 0.5 & $18.6-24.5$ & [58] \\
\hline E40 & Underwater wet welding & 150 & 66.3 & [59] \\
\hline E40 & In-air flux-cored arc welding & 0 & $<15$ & [59] \\
\hline IIW Standard & Welding & - & $<5$ & [38] \\
\hline \multirow[t]{3}{*}{ Ti-6Al-4V } & Repaired by In-air DMD & 0 & $0.0066 \%$ (wt.\%) & [49] \\
\hline & Repaired by ULDMD & 0.055 & $0.0095 \%$ (wt.\%) & [49] \\
\hline & AMS 4911L standard & - & $0.015 \%$ (wt.\%) & [60] \\
\hline
\end{tabular}

Note: The symbol * represents that the data were obtained by the authors

(1) Tensile stresses which are close to the yield strength are presented; (2) A critical number of diffusible hydrogen diffuses within the lattice; (3) The microstructure of the metal material is easily influenced by hydrogen cracking.

Table 3 summarizes the diffusible hydrogen content in samples prepared by underwater laser/arc welding/ cladding techniques. Note that the values of hydrogen contents of samples prepared by ULDMD are far below the standard for hydrogen content $(<5 \mathrm{~mL} / 100 \mathrm{~g})$ in the welded joint according to the International Institute of Welding (IIW) [38], as shown in Table 3. It indicates that formation of a stable local dry area is important for the control of diffusible hydrogen content ULDMD. The ultra-low level of diffusible hydrogen content in the deposited metal significantly reduces the risk of hydrogen embrittlement in underwater environments. In contrast, Table 3 shows that the diffusible hydrogen content 
in the samples by underwater automatic gas metal arc welding is in the range from 5 to $21 \mathrm{~mL} / 100 \mathrm{~g}$ [52], which are much higher than the underwater laser beam welding and higher than the standard of IIW. For the samples by wet welding [56-59], the diffusible hydrogen contents were much higher than that the standard of IIW, as shown in Table 3. Świerczyńska et al. [57] claimed that the hydrogen content could not be reduced by technological methods below $21 \mathrm{~mL} / 100 \mathrm{~g}$. Therefore, the application of drainage nozzles during underwater welding/cladding is necessary for the decrease in hydrogen content.

\section{Conclusions, Challenges and Prospects}

Many researchers have made unremitting research and exploration on underwater welding technology to expand the applications of this technology in the marine engineering. In this article, we presented an engineering overview of the underwater laser welding/cladding technique as one of the promising techniques for the on-site repair of marine metal materials. Current progress and situation, organization performance, underlying mechanisms and challenges about the underwater laser welding/cladding technique were summarized. In addition, some suggestions on the future research in underwater laser welding/cladding were provided.

\subsection{Conclusions}

(1) The recent developments of several kinds of drainage nozzles which play a decisive role in forming a stable local dry area in underwater welding/cladding were summarized. For the underwater laser welding, the gas drainage method can generate a stable local dry area in a shallow water depth which was approximately $3 \mathrm{~m}$, while the water drainage method can extend the water depth up to $30 \mathrm{~m}$. The drainage nozzle with hybrid gas and water drainage method was expected to obtain a better drainage quality at a larger water depth.

(2) Laser-material processing technology and microstructure-mechanical properties of underwater laser beam welded or cladded marine materials from the publications were summarized. Water had a slight influence on the ULBW when the thickness of water layer in the laser welding/cladding zone was less than $3 \mathrm{~mm}$. However, when the thickness of water layer in the laser welding/cladding zone was greater than $7 \mathrm{~mm}$, water had a strong hindering effect on the laser beam.

(3) An innovative powder-based ULDMD technique developed by the authors' research group was introduced in detail. How the underwater environment affects the convection, conduction and the metallurgical kinetics in the melt pool during ULDMD was presented. Mechanical properties of the $316 \mathrm{~L}$ stainless steel, HSLA-100 steel and Ti-6Al-4V titanium alloy fabricated by ULDMD were comparable to those fabricated by in-air DMD.

(4) For the samples fabricated by underwater wet arc welding, the diffusible hydrogen contents were much higher than that of the standard for hydrogen content $(5 \mathrm{~mL} / 100 \mathrm{~g})$ in the welded joint according to the International Institute of Welding (IIW). When the material was welded/cladded in the local dry area by underwater laser welding/cladding technique, diffusible hydrogen contents in the asbuilt materials were far below the standard of the IIW.

\subsection{Challenges}

Despite the advantages presented by the underwater laser welding/cladding technique, there are several challenges that might limit the application of this technique. Those challenges need to be overcame to achieve the full potential of this technique in the repair of marine metal materials.

(1) The control of the flow rates of several drainage gases to achieve a balance between the drainage effect and melt pool stability is difficult. In addition, the gas flow parameters are also different for different water depths and the processing databases at different water depths need to be built.

(2) Compared with that of underwater arc welding techniques, the material deposition rate of the underwater laser welding/cladding technique is relatively low. Comprehensive control of process parameters is particularly important.

(3) Compared with that of underwater arc welding techniques, the heat input of the underwater laser welding/cladding technique is small, leading to a fast cooling rate. The fast cooling rate can contribute to the formation of hardened microstructures. In addition, the fast cooling rate of the melt pool might limit the escape of the diffusible hydrogen, leading to a high generation probability of hydrogen induced cracks.

(4) The marine metal structures usually have different shapes. The damaged surfaces needed to be repaired usually have various angles $\left(0-180^{\circ}\right)$. When the underwater laser welding/cladding is carried out at a high angle, the stability of the melt pool might be deteriorated due to the effect of gravity. 
(5) Some features of the in-air laser welding/cladding, including complex inherent heat-treatment, repetitive rapid heating-cooling thermal cycles and steep temperature gradients, are involved in the underwater laser welding/cladding process. In addition, the underwater laser welding/cladding is also influenced by the water quenching effect. The water quenching effect would couple with the specific thermal history of the laser process and further increases the complexity of the thermodynamics and kinetics of the underwater laser melt pool. No detailed study has been made on the complex phenomenology of the thermal process and phase evolution in the marine metal materials.

\subsection{Prospects}

To date, several works have been reported for the successful fabrication of marine metal materials in underwater environments. Although some promising results of underwater laser welding/cladding processes on marine metal materials have been reported, there are still some important aspects that require further investigations. Here we propose several typical features which need more attention.

(1) According to the published data, the water depth was generally less than $200 \mathrm{~mm}$. When the water depth increases, some key issues including the drainage performance of drainage nozzles, lasermaterial interaction and hydrogen absorption capacity of melt pool at high pressure, become very complex and need to be evaluated in detail. Note that more efforts should be devoted to the optimization of drainage nozzle structures to improve their drainage performance when the underwater environment pressure increases with the increase in water depth.

(2) To further advance the fundamental understanding of the process-structure-property relationship of the marine metal materials by underwater laser welding/cladding, it is of significance to carry out multi-physics calculations and theoretical investigations about the underwater manufacturing process. Intensive attention should be paid to the numerical and experimental study on the interaction between the metal powders, laser beam and melt pool when the melt pool was surrounded by shielding gas and drainage gas under high pressure, which determines the formability of deposited materials. Those studies could shed light on the understanding of the heat and mass transfer, melt pool characteristics, densifications, etc in the underwater deposition process.

(3) It is urgent to optimize the underwater laser processing parameters and control their effects on diffusible hydrogen contents, defects formation, microstructural evolution, thermomechanical, thermodynamics-kinetics of metallurgical reaction in a deep underwater environment and corresponding mechanical properties. Those results could be used to tailor user-defined mechanical and physical properties of the repaired marine metal materials. It is important to emphasize that how to reduce the welding porosity and diffusible hydrogen content is a worthwhile project for improving the quality of deposited metal materials.

(4) Development of on-line monitoring of melt pool morphology, temperature field and spectral signals during underwater manufacturing process, will be beneficial to the fabrication of sound repaired structures with less defects and preferred microstructure and mechanical properties. In addition, the use of machine learning for automated defect detection and non-destructive testing may be useful tools in this field. Those studies are needed to ensure confidence in the repair performance of the marine metal materials, which is very important for the application of underwater laser welding/cladding technique on the marine engineering.

\section{Acknowledgements}

Not applicable.

\section{Authors' Contributions}

GS was in charge of the research project and the whole trial, review of existing research works and writing the manuscript. ZW carried out some literature review, compilation of strategies and execution of the case studies. YL proposed the outlines of the article. MC and KY helped to check the manuscript. ZN helped to revise the manuscript. All authors read and approved the final manuscript.

\section{Authors' Information}

Guifang Sun, born in 1982, is currently a professor and a PhD candidate supervisor at School of Mechanical Engineering, Southeast University, China. Her main research interests include laser additive manufacturing, underwater laser direct metal deposition and laser surface alloying.

Zhandong Wang, born in 1993, is currently a PhD candidate at School of Mechanical Engineering, Southeast University, China.

Yi Lu, born in 1988, obtained his PhD degree in mechanical engineering from Southeast University, China, in 2020

Mingzhi Chen, born in 1995, is currently a PhD candidate at School of Mechanical Engineering, Southeast University, China.

Kun Yang, born in 1994, is currently a PhD candidate at School of Mechanical Engineering, Southeast University, China.

Zhonghua Ni, born in 1967, is currently a professor and a PhD candidate supervisor at School of Mechanical Engineering, Southeast University, China. His main research interests include advanced manufacturing technology, and design and manufacture of Micro-Nano Biomedical Instruments. 


\section{Funding}

Supported by National Basic Scientific Research Project (Grant No.

JCKY2017110B001), and Jiangsu Provincial Postgraduate Research \& Practice Innovation Program of China (Grant No. KYCX20_0080).

\section{Competing Interests}

The authors declare no competing financial interests.

Received: 16 February 2021 Revised: 9 November 2021 Accepted: 30 December 2021

Published online: 28 January 2022

\section{References}

[1] C E Grubbs, T J Reynolds. Underwater welding: Seeking high quality at greater depths. Welding Journal, 1998, 77: 35-39.

[2] M Tamura, Y Makino, THino, et al. Development of underwater laser cladding and underwater laser seal welding techniques for reactor components (III). 16th International Conference on Nuclear Engineering, Orlando, 2008, 1-4.

[3] J L Zhu, X D Jiao. Applications of underwater laser welding in nuclear power plant maintenance. Second International Conference on Mechanic Automation and Control Engineering, Hohhot, 2011, 16: 2947-2950.

[4] J Labanowski. Development of under-water welding techniques. Welding International, 2011, 25(12): 933-937.

[5] H Chen, N Guo, X Zhang, et al. Effect of water flow on the microstructure, mechanical performance, and cracking susceptibility of underwater wet welded Q235 and E40 steel. Journal of Materials Processing Technology, 2020, 277: 116435 .

[6] I Habenicht, J F Santos, P Szelagowski, et al. Development of a nozzle for underwater laser beam welds. Proceedings of the International Conference on Offshore Mechanics and Arctic Engineering-OMAE, Materials Engineering. ASME, United State, 1996.

[7] Y Shi, K Sun, S Cui, et al. Microstructure evolution and mechanical properties of underwater dry and local dry cavity welded joints of $690 \mathrm{MPa}$ grade high strength steel. Materials, 2018, 11: 1-17.

[8] I Morita, K Owaki, H Yamaoka, et al. Study of underwater laser welding repair technology. Welding in the World, 2006, 50(7): 37-41.

[9] J Wang, Q Sun, S Zhang, et al. Characterization of the underwater welding arc bubble through a visual sensing method. Journal of Materials Processing Technology, 2018, 251: 95-108.

[10] Q Yang, Y Han, C Jia, et al. Impeding effect of bubbles on metal transfer in underwater wet FCAW. Journal of Manufacturing Processes, 2019, 45: 682-689.

[11] J Tomkow, J Labanowski, D Fydrych, et al. Cold cracking of S460N steel welded in water environment. Polish Maritime Research, 2018, 25: 131-136.

[12] K Sun, Y Hu, Y Shi, et al. Microstructure evolution and mechanical properties of underwater dry welded metal of high strength steel Q690E under different water depths. Polish Maritime Research, 2020, 27: 112-119.

[13] Y Zhai, L Yang, T He, et al. Weld morphology and microstructure during simulated local dry underwater FCTIG. Journal of Materials Processing Technology, 2017, 250: 73-80.

[14] G Rogalski, J Labanowski. Effect of welding parameters for a local dry cavity underwater welding process on the structure and properties of joints. Welding International, 2015, 29: 530-537.

[15] Y Hu, Y Shi, K Sun, et al. Microstructure evolution and mechanical performance of underwater local dry welded DSS metals at various simulated water depths. Journal of Materials Processing Technology, 2019, 264: 366-376.

[16] X Di, S Ji, F Cheng, et al. Effect of cooling rate on microstructure, inclusions and mechanical properties of weld metal in simulated local dry underwater welding. Materials and Design, 2015, 88: 505-513.

[17] D Fydrych, G Rogalski. Effect of underwater local cavity welding method conditions on diffusible hydrogen content in deposited metal. Welding International, 2013, 27: 196-202.

[18] H Gao, X D Jiao, C F Zhou, et al. Study on remote control underwater welding technology applied in nuclear power station. Procedia Engineering, 2011, 15: 4988-4993.
[19] G F Sun, Z D Wang, Y Lu, et al. Investigation on microstructure and mechanical properties of NV E690 steel joint by laser-MIG hybrid welding. Materials \& Design, 2017, 127: 297-310.

[20] N Guo, Y Fu, X Xing, et al. Underwater local dry cavity laser welding of 304 stainless steel. Journal of Materials Processing Technology, 2018, 260: 146-155.

[21] T Hino, M Tamura, Y Tanaka, et al. Development of underwater laser cladding and underwater laser seal welding techniques for reactor components. Journal of Power and Energy Systems, 2009, 3: 51-59.

[22] C Li, J Zhu, Z Cai, et al. Microstructure and corrosion resistance of underwater laser cladded duplex stainless steel coating after underwater laser remelting processing. Materials, 2021, 14: 4965.

[23] C Liu, N Guo, Q Cheng, et al. In situ formation of laser-cladded layer on thin-walled tube of aluminum alloy in underwater environment. Materials, 2021, 14: 4729.

[24] N Guo, X Xing, H Zhao, et al. Effect of water depth on weld quality and welding process in underwater fiber laser welding. Materials and Design, 2017, 115: 112-120.

[25] G J Shannon, J Watson, W F Deans. Investigation into the underwater laser welding of steel. Journal of Laser Applications, 1994, 6(4): 223-229.

[26] X Feng, X Cui, Wei Zheng, et al. Performance of underwater laser cladded nickel aluminum bronze by applying zinc protective layer and titanium additives. Journal of Materials Processing Technology, 2019, 266: 544-550.

[27] T Kojima, K Ohwaki, K Tsuchiya, et al. Development of underwater welding with high power YAG laser. Ishikawajima-Harima Giho, 1997, 37: 303-308.

[28] M Tamura, S Kawano, W Kouno. Development of underwater laser cladding and underwater laser seal welding techniques for reactor components (II). 14th International Conference on Nuclear Engineering, Miami, 2006.

[29] S Zhang, Z Wang, Y Yan, et al. Numerical simulation and innovative structure of drainage cover. 37th ASME International Conference on Ocean, Offshore and Arctic Engineering, Madrid, 2018.

[30] L Wang, F Xie, Y Feng, et al. Innovative methodology and database for underwater robot repair welding: A technical note. ISIJ International, 2017, 57: 203-205.

[31] Y Yamashita, T Kawano, K Mann. Underwater laser welding by 4 kW CW YAG laser. Journal of Nuclear Science and Technology, 2001, 38: 891-895.

[32] X Zhang, E Ashida, S Shono, et al. Effect of shielding conditions of local dry cavity on weld quality in underwater Nd:YAG laser welding. Journal of Materials Processing Technology, 2006, 174: 34-41.

[33] I Chida, N Mukai, W Kono. Development of multifunction laser welding head as maintenance technologies against stress corrosion cracking for nuclear power reactors. ICONE17-75138, Brussels, 2009.

[34] M Yoda, M Tamura, T Fukuda, et al. Underwater laser beam welding for nuclear reactors. 20th International Conference on Nuclear Engineering and the ASME 2012 Power Conference, Anaheim, 2012, 1-5.

[35] M Yasuhiro, M Yasuhiro, $\mathrm{H}$ Naoya, et al. The application of the welding technique at fillet groove by the YAG-laser repair-welding robot for underwater environment. 12th International Conference on Nuclear Engineering, Arlington, 2004.

[36] H Okihana, K Iwata, Y Miwa. Remote-controlled inspection robot for nuclear facilities in underwater environment. 17th International Conference on Nuclear Engineering, Brussels, 2009.

[37] Y Masaki, M Naruhiko, O Makoto, et al. Laser-based maintenance and repair technologies for reactor components. 12th International Conference on Nuclear Engineering, Arlington, 2004, 1-8.

[38] R Bucurel, G Hlifka. Laser beam welding process automates underwater repairs. Welding Journal, 2010, 89: 47-49.

[39] X Zhang, W Chen, E Ashida, et al. Relationship between weld quality and optical emissions in underwater Nd:YAG laser welding. Optics and Lasers in Engineering, 2004, 41: 717-730.

[40] Y Fu, N Guo, B Zhu, et al. Microstructure and properties of underwater laser welding of TC4 titanium alloy, Journal of Materials Processing Technology, 2020, 275: 116372.

[41] Y Fu, N Guo, Q Cheng, et al. In-situ formation of laser-cladded layer on Ti-6Al-4V titanium alloy in underwater environment. Optics and Lasers in Engineering, 2020, 131: 106104.

[42] Y Fu, N Guo, L Zhou, et al. Underwater wire-feed laser deposition of the Ti-6Al-4V titanium alloy. Materials \& Design, 2020, 186: 108284 
[43] Y Fu, N Guo, G Wang, et al. Underwater additive manufacturing of Ti-6Al-4V alloy by laser metal deposition: Formability, grain growth and microstructure evolution. Materials \& Design, 2021, 197: 109196.

[44] Y Fu, N Guo, C Zhou, et al. Investigation on in-situ laser cladding coating of the 304 stainless steel in water environment. Journal of Materials Processing Technology, 2021, 289: 116949.

[45] Z D Wang, G F Sun, Y Lu, et al. High-performance Ti-6Al-4V with graded microstructure and superior properties fabricated by powder feeding underwater laser metal deposition. Surface \& Coatings Technology, 2021, 408: 126778.

[46] Z D Wang, G F Sun, M Z Chen, et al. Investigation of the underwater laser directed energy deposition technique for the on-site repair of HSLA-100 steel with excellent performance. Additive Manufacturing, 2021, 101884.

[47] G F Sun, XT Shen, Z D Wang, et al. Laser metal deposition as repair technology for 316L stainless steel: Influence of feeding powder compositions on microstructure and mechanical properties. Optics and Laser Technology, 2019, 109: 71-83.

[48] G F Sun, S Yao, Z D Wang, et al. Microstructure and mechanical properties of HSLA-100 steel repaired by laser metal deposition. Surface \& Coatings Technology, 2021, 351: 198-211.

[49] Z D Wang, K Yang, M Z Chen, et al. Investigation of the microstructure and mechanical properties of Ti-6Al-4V repaired by the powder-blown underwater directed energy deposition technique. Materials Science \& Engineering A, 2022, 831: 142186.

[50] ASTM International, Standard Specification for Titanium-6Aluminum4Vanadium Alloy Castings for Surgical Implants (UNS R56406), F 1108-04: ASTM International 2004.

[51] S A E Aerospace. Titanium alloy bars, wire, forgings, rings, and drawn shapes 6Al-4V annealed. Aerospace Material Specification, 2007, 4928: 2007.

[52] J Labanowski, D Fydrych, G Rogalski. Underwater welding - A review. Advances in Materials Science, 2008, 8: 11-22.

[53] J Klett, T Wolf, H J Maier, et al. The applicability of the standard DIN EN ISO 3690 for the analysis of diffusible hydrogen content in underwater wet welding. Materials, 2020, 13: 1-17.

[54] P Wei, H Li, J Liu, et al. The effect of water environment on microstructural characteristics, compositional heterogeneity and microhardness distribution of $16 \mathrm{Mn} / 304 \mathrm{~L}$ dissimilar welded joints. Journal of Manufacturing Processes, 2020, 56: 417-427.

[55] J C Lippold. Welding Metallurgy and Weldability. John Wiley Sons: Hoboken, NJ, USA, 2014.

[56] D Fydrych, G Rogalski. Effect of shielded-electrode wet welding conditions on diffusion hydrogen content in deposited metal. Welding International, 2011, 25: 166-171.

[57] A Świerczyńska, D Fydrych, G Rogalski. Diffusible hydrogen management in underwater wet self-shielded flux cored arc welding. International Journal of Hydrogen Energy, 2017, 42: 24532-24540.

[58] H Chen, N Guo, K Xu, et al. In-situ observations of melt degassing and hydrogen removal enhanced by ultrasonics in underwater wet welding Materials \& Design, 2020, 188: 108482.

[59] H Chen, N Guo, C Liu, et al. Insight into hydrostatic pressure effects on diffusible hydrogen content in wet welding joints using in-situ X-ray imaging method. International Journal of Hydrogen Energy, 2020, 45: 10219-10226.

[60] S A E Aerospace. Titanium alloy, sheet, strip, and plate 6Al-4V annealed. AMS 4911L: Aerospace Material Specification, 2007.

\section{Submit your manuscript to a SpringerOpen ${ }^{\odot}$ journal and benefit from:}

- Convenient online submission

- Rigorous peer review

- Open access: articles freely available online

- High visibility within the field

- Retaining the copyright to your article

Submit your next manuscript at $\boldsymbol{\nabla}$ springeropen.com 